\title{
Simulation-Based Optimization of Hybrid Renewable Energy System for Off-grid Rural Electrification
}

\author{
Akinola Sunday Oladeji ${ }^{a, b^{*}}$, Mudathir Funsho Akorede ${ }^{b}$, Salihu Aliyuc, \\ Abdulrasaq Apalando Mohammeda, Adebayo Wahab Salami ${ }^{a, d}$ \\ ${ }^{a}$ National Centre for Hydropower Research and Development, University of Ilorin, Ilorin, Nigeria \\ ${ }^{b}$ Advanced Power and Green Energy Research Group, Department of Electrical and Electronics Engineering, University of Ilorin, \\ Ilorin, Nigeria \\ c Department of Telecommunication Engineering, Federal University of Technology Minna, Nigeria \\ ${ }^{d}$ Department of Water Resources and Environmental Engineering, University of Ilorin, Ilorin, Nigeria
}

\begin{abstract}
There is a need to develop an optimization tool that can be applied in the feasibility study of a hybrid renewable energy system to find the optimal capacity of different renewable energy resources and support the decision makers in their performance investigation. A multi-objective function which minimizes the Levelized Cost of Energy (LCOE) and Loss of Load Probability Index (LLPI) but maximizes the novel Energy Match Ratio (EMR) was formulated. Simulation-based optimization method combined with $\varepsilon$-constraint technique was developed to solve the multi-objective optimization problem. In the study, ten-year hourly electrical load demand, using the end-use model, is estimated for the communities. The performance of the developed algorithm was evaluated and validated using Hybrid Optimization Model for Electric Renewables (HOMER ${ }^{\circledR)}$ optimization software. The developed algorithm minimized the LCOE by $6.27 \%$ and LLPI by $167 \%$ when compared with the values of LCOE $(\$ 0.444 / \mathrm{kWh})$ and LLPI $(0.000880)$ obtained from the HOMER ${ }^{\circledR}$ optimization tool. Also, the LCOE with the proposed approach was calculated at $\$ 0.417 / \mathrm{kWh}$, which is lower than the $\$ 0.444 / \mathrm{kWh}$ obtained from HOMER ${ }^{\circledR}$. From environmental perspective, it is found that while $141,370.66 \mathrm{~kg} \mathrm{of} \mathrm{CO}_{2}$ is saved in the base year, $183,206.51 \mathrm{~kg}$ of $\mathrm{CO}_{2}$ is saved in the ninth year. The study concluded that the approach is computationally efficient and performed better than HOMER ${ }^{\circledR}$ for this particular problem. The proposed approach could be adopted for carrying out feasibility studies and design of HRES for Off-Grid electrification, especially in the rural areas where access to the grid electricity is limited.
\end{abstract}

Keywords: Renewable energy technologies, energy match ratio, loss-of-load probability, rural electrification, simulation based optimization approach.

Article History: Received: $1^{\text {st }}$ July 2020; Revised: 17 Jan 2021; Accepted: $18^{\text {th }}$ March 2021; Available online: $2^{\text {th }}$ April 2021

How to Cite This Article: Oladeji, A.S., Akorede, M.F., Aliyu, S., Mohammed, A.A., and Salami, A.W. (2021) Simulation -Based Optimization of Hybrid Renewable Energy System for Off-Grid Rural Electrification. Int. Journal of Renewable Energy Development, 10(4), 667-686 https://doi.org/10.14710/ijred.2021.31316

\section{Introduction}

The global concerns of climate change which is largely due to increase in consumption of fossil fuels as a result of the rising global electrical energy demand is one of the factors liable for the worldwide awareness in the use of renewable energy resources for rural electrification (Ahmadi et al. 2018; Sadeghzadeh et al. 2019). Furthermore, a comprehensive survey of the open literature (Lan et al. 2015; Cho and Kleit 2015; Zhao et al. 2015; Zakeri and Syri 2015) has established that application of battery bank in absorbing excess energy is among the utmost efficient answers to guarantee the stability, affordability and reliability of power supply. Additionally, the Kyoto Protocol voted in year 1997, compels the industrialized countries to minimize their greenhouse gases emissions to a threshold. These factors, among others, contribute to the amplified infiltration of non-fossil based energy sources in our power system today. Unfortunately, the unpredictable nature of most non-fossil based energy resources and high cost associated with single renewable energy source has made it uneconomical to meet up with the required hourly energy demand.

In this direction, a hybrid renewable energy system which is a grouping of at least two renewable energy technologies is an exceptional key for the energization of rural settlements to satisfy the hourly energy demand reliably and economically. Hybrid energy systems are crucial sources of energy for commercial users such as shops, schools (primary and secondary) and clinics in offgrid rural communities. The major goal of the system is to deliver a reliable 24-hour quality electric power in rural communities daily. However, the major challenge with HRES is the optimal sizing of its major components to attain a design that is technically and economically feasible. The more the number of the components

\footnotetext{
* Corresponding author: akinsun3k@yahoo.co.uk
} 
involved, the more the complexity in the design of the HRES as a result of the random characteristic of the renewable energy resources and the trade-off between system reliability and cost.

In the past, efforts have been made to explore a moderately straight-forward technique for designing a HRES using different multi-objective optimization methods. Generally, optimization techniques both traditional and modern are classified into three groups. They are the traditional optimization techniques, the intelligence search, and the non-quantity approaches to resolve any indecisions exist in both the objectives and constraints (Zhu 2015). A number of these optimization approaches employed for HRES shall be reported in details in the coming paragraphs. Zahraee et al. (2016) presented a comprehensive review and evaluation of various available artificial intelligence approaches for the optimal sizing of HRES, some of which are discussed here (Mohamed 2016).

The prominent advantages of PSO such as easiness, efficacy and cheap computational cost, has made it to gain weighty popularity and developments (Gao et al. 2015). In latest ages, numeral of researchers has improved PSO to tackle numerous HRES optimization problems. For example, Amer et al. (2013) applied PSO to determine the optimal size of the components of a HRES containing wind turbine, solar PV module and loads typical of residential buildings. Similarly, Boonbumroong et al. (2011) employed PSO to determine the configuration with minimum lifecycle cost of a stand-alone PV/wind/diesel system to supply a certain load just as PSO algorithm was employed in (Bashir \& Sadeh 2011; Kaviani et al. 2009; Ardakani et al. 2010; Bashir \& Sadeh 2012; Askarzadey et al. 2015) for optimum sizing of HRES comprising different renewable energy components. Again, Hakimi \& Moghaddas (2009) utilized PSO to select the configuration with minimum total cost of a detached hybrid energy system which considers electrolyzers and an anaerobic reactor as part of the HRES components. Also, an optimization problem for a HRES of solar PV and wind energy capacity coordination for a time-of-use rate industrial user, was solved using PSO (Lee \& Chen 2009).

Similarly, Wang \& Singh (2009) used multi-objective PSO algorithm to calculate the optimal capacity of a hybrid PV/wind/battery energy system which minimizes cost, emission while maximizes reliability, without tackling the issues of load management. Yet, Borhanazad et al. (2014) intended a micro-grid scheme, involving wind and PV system as a primary energy sources with battery bank to absorb excess generated energy and diesel generator for emergency situation, via multi-objective particle swarm optimization (MOPSO). Additionally, Masoud \& Tarek (2014) presented a dynamic multiobjective particle swarm optimization (DMOPSO) technique for the selection of the optimal configuration for HRES. In the same vein, Fodhil et al. (2019) suggested a combination of Particle Swarm Optimization (PSO) and $\varepsilon$ constraint method to reduce the overall cost of the system, net load, and $\mathrm{CO}_{2}$ emissions as it optimizes a standalone hybrid PV-diesel-battery energy system to satisfy the required energy demand of 20 households.

Numerous authors have used related multi-objective evolutionary algorithms and other techniques for an appropriate sizing of different components of HRES. A number of these optimization approaches employed by different authors for HRES shall be briefly reported as follows. Katsigiannis et al. (2010) modeled a multiobjective optimization approach to produce a Pareto front to reduce the sum of energy cost and overall emissions of a HRES throughout its lifespan by means of nondominated sorting genetic algorithm (NSGA). Das et al. (2019) carried out a study to obtain a technical and economical optimal design of an off-grid hybrid energy systems comprises of solar photovoltaic, biogas generator, pumped storage hydro and battery energy storage system using metaheuristic optimization methods for a wireless transmitter station located in India. The results of water cycle algorithm and moth-flame optimization were appraised and compared with Genetic Algorithm.

Forough \& Roshandel (2017) presented a multiobjective receding horizon optimization (MO-RHO) method to obtain the best arrangement of HRES involving solar PV, wind turbine, battery bank and diesel generator. Bourennani et al. (2015) presented optimal design of HRES using the state-of-the-art multi-objective optimization (MOO) metaheuristics, just as Kaabeche \& Bakelli (2019) considered ant lion optimizer algorithm (ALO), Grey Wolf optimizer algorithm (GWO), Krill Herd algorithm (KH) and Jaya algorithm for the same purpose. To lessen the total annualized cost of the system in the face of power balance constraint, Hadidian-Moghaddam et al. (2016) recommended a procedure for the best arrangement of a stand-alone hybrid PV/wind/battery power generation system (HPWGS) using a Grey Wolf Optimizer. In the same vein, utilizing a discrete version of harmony search (HS), Maleki \& Askarzadeh (2014) carried out the modeling and optimal sizing of a $\mathrm{PV} /$ wind/diesel/battery hybrid scheme for an off-grid application.

Ren et al. (2018) formulated a multi-criteria optimization approach for investment strategy and administration of the operation a hybrid energy system. The non-dominated sorting genetic algorithm II (NSGAII) was used to solve the problem. Similarly, Kamjoo et al. (2016) presented the use of NSGA-II algorithm for the design of a HRES containing wind turbine, solar PV and battery with the aim of reducing the scheme whole cost but maximizing the scheme reliability. In the same vein, Huang et al. (2019) presented this same NSGA-II to produce the Pareto set for optimization of a stand-alone PV-hydrogen-retired EV battery hybrid energy system. The authors proposed the reuse of aged electric vehicle batteries (REVBs) as a renewable energy system.

An approach for sizing of hybrid plants, through implementation of a momentary simulation model joined with an evolutionary algorithm, was presented by (Starke et al. 2018). The simulation module was used for a case study bearing in mind the features of the location in the northern Chile.

Roberts et al. (2018) suggested the use of a probabilistic simulation-based MOO method to tackle the optimal combination of the components of the hybrid power systems. Abdelkader et al. (2018) proposed the application of the multi-objective genetic algorithm to size a PV/Wind Hybrid Energy Storage System (HESS) which minimizes loss of power supply probability (LPSP) and the total cost of energy (TCE). Perera et al. (2013) focused their work on hybridizing MOO techniques with a multicriterion decision making (MCDM) method to help the decision makers in designing HRES. On the other hand, Suhane et al. (2016) presented Ant colony optimization technique for sizing and performance analysis of a 
standalone HRES comprising wind turbine and solar photovoltaic system for an un-electrified rural settlement in central region of India.

Jadidbonab et al. (2020) proposed a novel model of the energy hub, known as the virtual energy hub (VEH). The proposed VEH is operated, according to the different energy carriers and facilities in addition to maximizing of its revenue by participation on the various local energy markets. Gholinejad et al. (2020) presented a hierarchical energy management system (HEMS) for multiple home energy hubs in the neighbourhood grid (MHEHNG) with the objectives of maximizing economic profit and shaving the peak of upstream grid. In addition, simulator was implemented in the MATLAB/GUI software environment to enable the performance evaluation of the HEMS.

Nazari-Heris et al. (2020) proposed a multi-objective two-stage stochastic unit commitment scheme for integrated gas and electricity networks by considering P2G technology and demand response (DR) programs in addition to high penetration of wind turbines. Marzband et al. (2018) presented a smart Transactive energy (TE) framework with objective of ensuring that home microgrids (H-MGs) can cooperate with each other in a multiple H-MG system by establishing alliances for gaining competitiveness in the market.

The technique of multi-objective-techno-economicenvironmental optimization is proposed for planning electric vehicle charging/discharging was presented by Das et al. (2020). The modelling and optimization of energy cost for the end users, battery degradation as well as grid interaction and $\mathrm{CO}_{2}$ emissions in the home microgrid context were carried out while ensuring frequency regulation. Mirzaei et al. (2019) proposed three solutions to overcome the challenges of gas system constraints and the uncertainty of wind power which are: 1) using information-gap decision theory (IGDT) based robust approach to tackle the uncertainty produced by the intrinsic nature of wind power; 2) Incorporation of compressed air energy storage (CAES), and demand response (DR) in day-ahead scheduling; and 3) considering flexible ramping products so as to guarantee dependable operations.

Tregambi et al. (2021) presented the modelling of a concentrated solar power (CSP)/photovoltaics hybrid power plant for capturing carbon dioxide and exploitation through calcium looping and methanation. The integrated procedure was studied via model computations. Mahmoudi et al. (2021) focused their work on the sizing of a hybrid energy system comprising of solar photovoltaic modules and wind conversion energy systems plus/without the storage backup system to lessen economic costs and increase reliability. A novel technique was proposed according to the integration of fuzzy logic controller and harmony search algorithm. Wu et al. (2021) proposed the synergetic relations of electricity, thermal and gas energy flows, in which the biogas-solar-wind complementarities are fully considered and the digester heating is applied to provide an appropriate temperature for biogas production from anaerobic digestion. A multitasking multi-objective optimization algorithm, MOMFEA-II was proposed to handle the problem. Singh and Bansal (2019) presented reformed electric system cascade analysis (RESCA) method for optimization of HRES comprising of wind energy conversion system (WECS), solar photovoltaic (PV) system, battery energy storage system, and non-renewable sources.
Apart from the aforementioned classical and advanced optimization techniques, the most extensively software employed for optimal sizing of HRES is HOMER software. Other alternative software tools used for optimization of HRES include HYBRIDS, HYBRID2, RET Screen, TRNSYS, IHOGA, etc. HOMER is more or less a freely available software application created by the National Renewable Energy Laboratory in the United States in 1993. It is used for design and evaluation of different options of HRES comprising different distributed energy resources, taking into account technical and financial considerations.

Several researchers (Kamel \& Dahl 2005; Khan et al. 2005; Shaahid \& Elhadidy 2007; Limmeechokchai \& Chawana 2007; Himri et al. 2008; Dalton et al. 2008; Nfah et al. 2008; Weis \& Ilinca 2008; Setiawan et al. 2009; Kusakana et al. 2009; Demiroren \& Yilmaz 2009; Abdul Razak et al. 2010; Aziz et al. 2019; Ariyo et al. 2018) have used the software to either perform techno-economic optimisation analysis of a proposed HRES or to validate their own developed method using it as a reference. For example, Aziz et al. (2019) used HOMER optimization software for techno-economic and environmental evaluation of various hybrid systems to satisfy the electricity needs of a conventional rural village in Iraq while (Ariyo et al. 2018) employed it only to validate the proposed method. Tsai et al. (2020) investigated the techno-economic feasibility analysis of stand-alone diesel system, stand-alone PV/storage system, PV/diesel hybrid system, PV/diesel/storage hybrid system for the Pratas island in Taiwan. The Hybrid Optimization Models for Energy Resources (HOMER) was employed to simulate the techno-economics of the indicated hybrid energy systems. However, one major limitation to the use of HOMER is its failure to tailor the mathematical modelling and the sizing technique for optimization as desired by the user-defined constraints and modelling equations (Shaahid \& Elhadidy 2007).

In the related literature, there is absence of studies that reflect the trade-off between system levelized cost of energy, system reliability and the novel energy match ratio. Additionally, there are not sufficient algorithms developed to handle the stochastic analysis of the design process of HRES by incorporating operating spinning reserve. Furthermore, existing tools do not deal with producing energy simultaneously for different types of electrical energy user class. The focus of the current research work is therefore to adopt the simulation-based optimization method combined with $\varepsilon$-constraint technique. Literature has revealed that the simulationbased optimization method is a developing technique which mongrelizes optimization techniques into simulation evaluation. PSO is preferred because of its ease of implementation as it requires few parameters to be changed. It is equally capable of tackling tough cost functions with many local minima, thereby overcoming the shortcoming of the metaheuristics, which cannot assure a global optimal solution (Kamjoo et al. 2016). The $\varepsilon$-constraint technique is a special method that is usually used to turn a number of objective functions to constraints bounded by given target levels $\left(\varepsilon_{\mathrm{i}}\right)$ while the preferred objective function is chosen to be optimized. The nondominated results to the optimization problem can be found by changing the $\varepsilon$. However, despite the existing works in the design and optimization of HRES in the energy community, the proposed approach in this study is 
to further demonstrate a contribution to the existing knowledge.

The present work considers three objective functions, namely: minimization of the levelized cost of energy (LCOE), minimization of loss-of-load probability index $(L L P I)$ and maximization of a novel energy match ratio $(E M R)$. The proposed approach also incorporates the spinning operating reserve so as to achieve a practical compromise among the objective functions. By definition, the spinning operating reserve is the spare generating capacity that is available to the grid by intensifying the electric power output of generators that are already linked to the power network. The goal of the $\varepsilon$-constraint technique in this study is to minimize the $L C O E$ while $L L P I$ and EMR are taken as constraints bound within the permissible limits. One of the main benefits of the proposed approach is computational efficiency since it does not require the unnecessary maneuver of ranking and dual comparison which are computationally complex (Sharafi and El-Mekkawy 2014). A case study is conducted for a group of rural settlements in Nigeria. Notwithstanding, the proposed approach could be adopted in carrying out feasibility studies and design of HRES for off-grid applications in any location on the globe having potentials for solar PV system and small hydropower.

To completely eliminate emissions associated with diesel engine generator, this study does not consider diesel generator in its scheme, more so as rural dwellers are hardly financially buoyant to cope with the running and repair cost of diesel generator. Instead, the study has incorporated the spinning operating reserve and maximization of energy match ratio to achieve a HRES with $100 \%$ renewable energy resources. The proposed HRES equally considers incorporation of small hydropower, which is missing in virtually all the existing works. The roadmap for the remainder of this paper is illustrated as follows. The mathematical models for different components of the HRES are presented in Section 2 . The essence is to evaluate the energy potential of each of the components as well as the electrical load demand. Section 3 is dedicated to the description of the multi-objective problem formulation. The solution approach as it applies to the problem at hand is exhibited in Section 4. The results to different scenarios of the optimization problem are given in Section 5 while the conclusion is presented in Section 6 .

\section{Materials and methods}

\subsection{Models for hybrid energy system components}

Modelling of the considered components of the proposed hybrid energy system is described in this section. The proposed hybrid energy system which comprises small hydropower generating set, solar PV array, storage batteries, charge controller, and bidirectional DC/AC power inverter, is represented in Fig. 1. In order to explore how possible change of the capacity with the corresponding cost per unit of input parameters may influence the optimal solution produced by the proposed solution approach under a specific number of assumptions, three different scenarios were considered.

\subsubsection{Modelling of energy from small hydropower}

Hydro-electric power is the power acquired from the energy of flowing water. The potential energy of water can be harnessed by converting it into kinetic energy which is transformed to mechanical energy by permitting the water to run across the water turbine runner. The mechanical energy is then used to spin a generator connected to the shaft of hydraulic turbine. The net head, $\mathrm{H}_{\mathrm{nt}}(\mathrm{m})$ is estimated using Eqn. (1). Meanwhile, the developed layout for various losses from forebay to the power house is represented in Fig. 2.

$H_{n t}=H_{g r}-\left\{h_{f}+h_{t r}+h_{b}+h_{o}\right\}$

where:

- $H_{g r}$ is gross head (m),

- $h_{f}$ is a frictional loss $(\mathrm{m})$,

- $h_{t r}$ is a trash rack loss (m),

- $\quad h_{b}$ is losses due to bend (m), and

- $h_{o}$ is outlet losses (m).

The electrical power developed by a single small hydropower generating unit $\left(P^{s}\right)$ is given in Eqn. (2) as:

$$
P^{s}=\left\{\begin{array}{lc}
\rho \times Q \times H_{n} \times \eta_{t u} \times \eta_{g} \times 9.81 & \text { for } Q_{\min } \leq Q<Q_{\max } \\
\rho \times Q_{\text {max }} \times H_{n} \times \eta_{t u} \times \eta_{g} \times 9.81 & \text { for } Q \geq Q_{\max } \\
0 & \text { for } Q<Q_{\min }
\end{array}\right.
$$

where:

- $\rho$ is the density of water in $\mathrm{kg} / \mathrm{m}^{3}$,

- $\eta_{t u}$ is the efficiency of turbine,

- $\eta_{g}$ is the efficiency of generator,

- $Q_{\text {min }}$ is the minimum discharge of the selected hydro turbine, and

- $Q_{\max }$ is the peak discharge of the selected hydro turbine.

The total hourly energy production from the total number of small hydropower generating unit system $\left(E_{t}^{S H P}\right)$ can be calculated by Eqn. (3) as:

$E_{t}^{S H P}=E_{t}^{S} \times N_{S H P}$

Where:

- $\quad N_{S H P}$ is the optimal number of small hydro turbine generating units to be determined by optimization algorithm, and

- $E_{t}^{s}$ is the energy generated by a single small hydropower generating unit.

The annual energy generated from the total number of small hydropower generating unit system $\left(E_{S H P}^{A N}\right)$ can be calculated by Eqn. (4).

$$
E_{S H P}^{A N}=\sum_{t=1}^{t=8760} E_{t}^{S H P}
$$




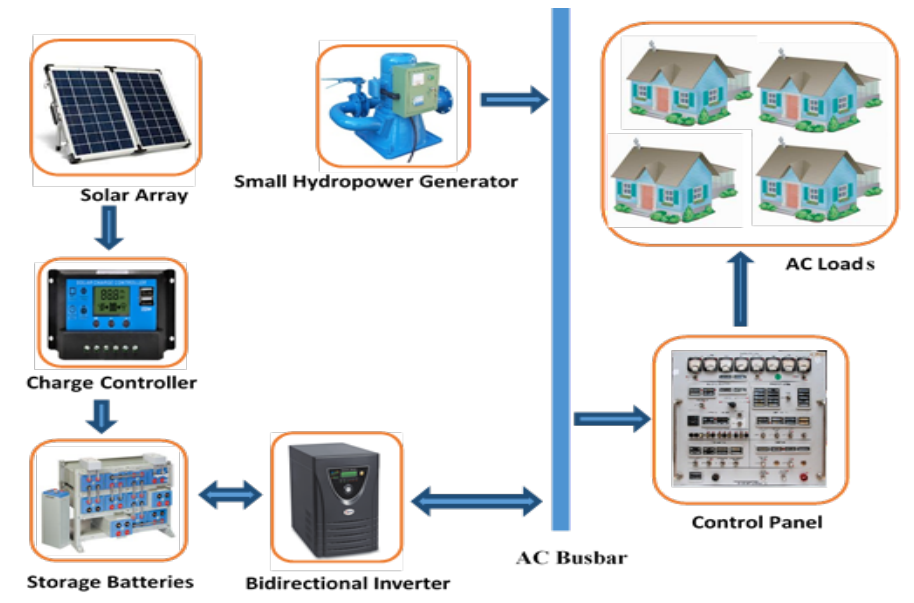

Fig. 1 Illustration of the Proposed Hybrid Energy System.

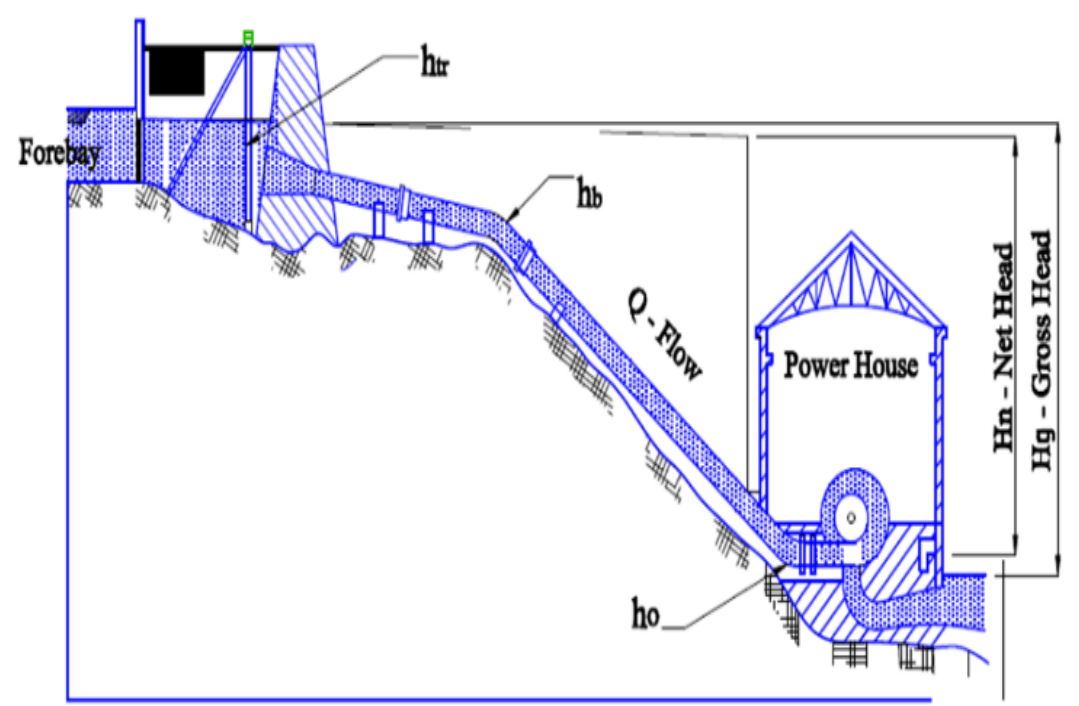

Fig. 2 Developed Layout for various Losses from Forebay to Power House.

\subsubsection{Modelling of energy from solar photovoltaic system}

The yield power of a solar photovoltaic panel at any period is relative to the solar solation value at that particular time. The electrical power produced at time $t$ by a single solar PV is calculated as given in Eqn. (5) (Borhanazad 2014).

$$
P_{t}^{p}=P_{R P} \times \frac{G_{t}^{I}}{G_{r e f}^{I}} \times\left[1+K_{t}\left(\left(T_{a m b}+\left(0.0256 \times G_{t}^{I}\right)\right)-T_{r e f}\right)\right]
$$

where $P_{R P}$ is rated power, $G_{t}^{I}$ is solar insolation at a time t $\left(\mathrm{W} / \mathrm{m}^{2}\right), G_{r e f}^{I}$ is $1000 \mathrm{~W} / \mathrm{m}^{2}, T_{\text {ref }}$ is $25^{\circ} \mathrm{C}, K_{t}$ is $-3.7 \times 10^{-3}$ $\left(1 /{ }^{\circ} \mathrm{C}\right), T_{a m b}$ is the ambient temperature $\left({ }^{\circ} \mathrm{C}\right)$.

The total hourly energy production from the total number of PV system $\left(E_{t}^{P V}\right)$ can be calculated by Eqn. (6) as:

$E_{t}^{P V}=E_{t}^{p} \times N_{P V}$

where $N_{P V}$ is the optimal number of solar PV.

The total number of PV modules $\left(N_{P V}\right)$ can be calculated by Eqn. (7), whereas the number of solar modules in series configuration can be calculated using Eqn. (8).

$N_{P V}=N_{P V}^{s} \times N_{P V}^{p}$

$$
N_{P V}^{S}=\frac{V_{b u s}}{V_{P V}}
$$

where $V_{\text {bus }}$ is the DC bus voltage, $V_{P V}$ is the nominal voltage of a single $\mathrm{PV}$, and $N_{P V}^{p}$ is the total number of modules in parallel.

By incorporating the spinning operating reserve, the total hourly energy production from the total number of PV system $\left(E_{t}^{O P V}\right)$ can be calculated from Eqn. (9), just as the annual energy production from the total number of solar modules $\left(E_{P V}^{A N}\right)$ can be calculated by Eqn. (10).

$E_{t}^{O P V}=\left(E_{t}^{p} \times N_{P V}\right)+\left(\% P V \times E_{t}^{P V}\right)$

$E_{P V}^{A N}=\sum_{t=1}^{t=8760} E_{t}^{O P V}$

\subsubsection{Modelling of electrical load demand}

The hourly electrical loads $\left(L D_{t}\right)$ can be expressed by Eqn. (11).

$$
\begin{array}{r}
L D_{t}=\sum_{q}^{u} N_{q} \times\left(\sum _ { r = 1 } ^ { S } \quad \left[\left(P_{q, r} \times n_{q, r} \times \Delta t\right)+\left(P_{q, r}^{s b y} \times n_{q, r}^{s b y} \times\right.\right.\right. \\
\Delta t)])
\end{array}
$$

where : 
- $\quad P_{q, r}$ is the power used by a device $\mathrm{r}$ in a particular defined consumer sort q,

- $n_{q, r}$ is total of appliances $\mathrm{r}$ in a defined consumer sort q,

- $\quad \mathrm{S}$ is the overall electrical appliances considered,

- $n_{q, r}^{s b y}$ is number of electrical device $\mathrm{r}$ in a defined consumer sort $q$ in standby, and

- $\quad P_{q, r}^{s b y}$ is the electrical power that is consumed by a device $r$ in a defined user sort $q$ in standby.

Incorporating the spinning operating reserve, the total hourly electrical energy demand $\left(E_{t}^{O P}\right)$ can be calculated by Eqn. (12). The classes of consumer considered in this study are residential and small commercial consumers.

$E_{t}^{O P}=L D_{t}+\left(\% L \times L D_{t}\right)$

where $\% L$ is the electrical load operating reserve.

\subsubsection{Modelling of battery output energy}

As a results of the intermittency characteristics of the non-fossil based energy sources, the battery is utilized as the energy storage scheme to regulate any excess or shortage energy produced. The utmost size of the battery bank that is needed to satisfy the load demand is calculated using Eqn. (13).

$E_{\text {bat }}^{\max }=\frac{E^{O P} \times D_{A}}{(D O D)_{\max } \times \eta_{\text {bat }} \times \eta_{\text {inv }}}$

Where:

- $D_{A}$ means days of autonomy, which is usually between 2-5 days,

- $(D O D)_{\max }$ is the utmost depth-of-discharge for the battery,

- $\eta_{\text {bat }}$ is the efficiency of battery, and

- $\eta_{\text {inv }}$ is the efficiency of inverter.

Similarly, the lowest state-of-charge of battery bank $\left(E_{b a t}^{\mathrm{min}}\right)$ is calculated by the $(D O D)_{\max }$ as shown in Eqn. (14). The quantity of batteries $\left(N_{b a t}\right)$ can be calculated by Eqn. (15).

$E_{\text {bat }}^{\min }=\left(1-(D O D)_{\max }\right) \times C_{b a t}$

$N_{b a t}=N_{b a t}^{s} \times N_{b a t}^{p}$

Where:

- $\quad N_{\text {bat }}$ is the quantity of batteries, a decision variable to be determined by optimization algorithm, and

- $\quad N_{b a t}^{p}$ is the quantity of batteries in parallel.

If adequate energy is delivered by generation sources then, the net energy would charge the batteries. The energy that is available for battery charging at time $t$ is given in Eqn. (16).

$E_{t}^{b a t}=E_{t-1}^{b a t}+\left(E_{t}^{S H P}+E_{t}^{O P V}-E_{t}^{O P}\right) \times \eta_{c h a} \times \eta_{c g c}$
Where:

- $E_{t}^{\text {bat }}$ and $E_{t-1}^{\text {bat }}$ are the state-of-charge of the battery at time $t$ and $t-1$ respectively,

- $\eta_{c h a}$ is the charging efficiency of the battery bank,

- $\eta_{c g c}$ is the efficiency of the charge controller. and

- $E_{t}^{O P}$ is the total electrical energy demand at time $\mathrm{t}$ by incorporating operating reserve.

However, in the event that the available generated energy fails to deliver adequate energy to balance the load, then, the batteries will be discharged according to Eqn. (17). The net load demand $\left(E_{t}^{N L}\right)$ to be supplied by the battery is given in Eqn. (18).

$E_{t}^{b a t}=E_{t-1}^{b a t}-E_{t}^{N L} /\left(\eta_{d c h} \times \eta_{i n v}\right)$

$E_{t}^{N L}=E_{t}^{O P}-\left(E_{t}^{S H P}+E_{t}^{O P V}\right)$

Where:

- $\quad \eta_{d c h}$ is the battery discharge efficiency, and

- $\eta_{i n v}$ is the efficiency of inverter.

\subsection{Problem formulation}

The optimization problem is expressed as a multiobjective task with three objective functions and constraints.

\subsubsection{The objective functions}

The objective functions considered in this study are minimization of levelized cost of energy (LCOE), minimization of loss-of-load probability index $(L L P I)$ and maximization of energy match ratio $(E M R)$. The decision variables are $\left[N_{S H P}, N_{P V}, N_{b a t}\right]$ where $N_{S H P}, N_{P V}, N_{b a t}$, are numbers of small hydropower generating unit, numbers of solar photovoltaic modules, and number of batteries respectively.

\subsubsection{Minimization of levelized cost of energy (LCOE)}

$L C O E$ is the cost per unit of electrical energy in $\mathrm{kWh}$. It can be stated as the ratio of annualized cost of the HES to the overall yearly electrical energy produced by the system. It is formulated in this work as an economic indicator. The annual energy produced from all the sources is evaluated using Eqn. (19).

$E^{A E G}=E_{S H P}^{A N}+E_{P V}^{A N}$

where $E^{A E G}, E_{S H P}^{A N}$, and $E_{P V}^{A N}$ are the total annual energy generations from all the generation resources, total annual generation from small hydropower generating system, total annual energy generation from solar photovoltaic generators respectively. The (TAC) includes the annualized capital cost (ANCC), yearly cost of operation and maintenance $(A O M C)$, yearly cost of replacement $(A N R C)$. The total annualized cost of the system $(T A C)$ can be calculated with the expression in Eqn. (20). 


$$
\begin{aligned}
& T A C=N_{S H P} \times\left[\left(C_{I, S H P} \times C R F\right)+\left(C_{S H P}^{m t h} \sum_{t=1}^{8760} E_{t}^{s}\right)\right]+N_{P V} \times\left[\left(C_{I, P V} \times C R F\right)+\left(C_{P V}^{m t h} \sum_{t=1}^{8760} E_{t}^{p}\right)\right] \\
& +N_{b a t} \times\left[\left(C_{I, b a t} \times C R F\right)+\left(C_{r b a t} \times R_{b a t} \times S F F(i, L)\right)\right]+N_{\text {inv }} \times\left[\left(C_{I, i n v} \times C R F\right)\right]+\left[\left(C_{I, \text { ggc }} \times C R F\right)\right]
\end{aligned}
$$

where:

- $C_{I, S H P}, C_{I, P V}, C_{I, \text { bat }}, C_{I, \text { inv }}, C_{I, c g c}$, are the per capital cost per unit of small hydropower generating unit, solar panel, battery, bidirectional power inverter, charge controller,

- $\quad C R F$ is capital recovery factor,

- $\quad S F F$ is sinking fund factor,

- $C_{S H P}^{m t n}$ is maintenance cost per $\mathrm{kWh}$ for SHP,

- $C_{P V}^{m t n}$ is maintenance cost per $\mathrm{kWh}$ for PV,

- $C_{\text {rbat }}$ is the cost of replacing a unit of battery, and

- $R_{b a t}$ is the number of times the battery will be replaced.

The capital recovery factor $(C R F)$ could be defined as the annual loan payment on $\$ 1$ borrowed for $R$ years at interest rate $i$. Its expression is presented in Eqn. (21).

$$
C R F=\frac{i(1+i)^{R}}{(i+1)^{R}-1}
$$

Where:

- $\quad R$ is the life span of the system which has been taken to be the life span of the solar PV, as a result of its expected lengthy life span in comparison to other components,

- $\quad i$ is the interest proportion.

The interest proportion comprises of nominal interest rate (ir) and inflation rate $(f)$ as given in Eqn. (22).

$i=\frac{(i r-f)}{(i r+f)}$

The sinking fund factor which is a ratio to determine the future values of a runs of identical cash movements is expressed in Eqn (23).

$\operatorname{SFF}(i, R)=\frac{i}{(1+i)^{R}-1}$

The LCOE is given in Eqn. (24) as:

$L C O E=\frac{T A C}{E^{A E G}}\left(\frac{\$}{k W h}\right)$

Where:

$$
\text { - } E^{A E G}=f\left(N_{S H P}, N_{P V}, N_{b a t}\right)
$$

\subsubsection{Minimization of loss-of-load probability index}

The loss of load for respective time period within one year is given in Eqn. (26).

$$
L L P I=\frac{\left.\sum_{t=1}^{t=8700}\left[E_{t}^{O P}-\left[\left(E_{t}^{s} \times N_{S H P}\right)+\left(\left(E_{t}^{P} \times N_{P V}\right)+\left(\% P V \times E_{t}^{P} \times N_{P V}\right)\right)+\left(\left(N_{b} \times E_{n}\right)-E_{b a t}^{\text {mix }}\right)\right)\right]\right]}{\sum_{t=1}^{t=870} E_{t}^{O P}}
$$

It is so desired in this study to minimize this function so as to maximize the availability of power supply to the customers.

\subsubsection{Maximization of energy match ratio}

The EMR between the demand and the supply profile is formulated as described by the expression given in Eqn. (27). It is a novel expression formulated in this study to match the demand with the supply, moment by moment.

$$
E M R=\frac{\left.\left.\sum_{t=1}^{t=8760}\left(E_{t}^{O P}-d\right) \cdot\left(\left(E_{t}^{P} \times N_{P V}\right)+\left(\% P V \times E_{t}^{P} \times N_{P V}\right)\right)+\left(E_{t}^{s} \times N_{S H P}\right)\right)-s\right)}{\sqrt{\left.\left.\sum_{t=1}^{t=8760}\left(E_{t}^{O P}-d\right)^{2} \cdot \sum_{t=1}^{t=8760}\left(\left(E_{t}^{P} \times N_{P V}\right)+\left(\% P V \times E_{t}^{P} \times N_{P V}\right)\right)+\left(E_{t}^{s} \times N_{S H P}\right)\right)-s\right)^{2}}}
$$

where:

$$
\begin{aligned}
\text { - } & d=\frac{\sum_{t=1}^{t=8760} E_{t}^{O P}}{8760}, \text { and } \\
\text { - } \quad s= & \frac{\sum_{t=1}^{t=8760}\left(E_{t}^{O P V}+E_{t}^{S H P}\right)}{8760}
\end{aligned}
$$

The $E M R$ is interpreted as presented below:

- $|\mathrm{EMR}|=1$ Perfect linear relationship between energy from renewable resources and load demand

- $0.5 \leq|\mathrm{EMR}|<1$ Stronger relationship between energy from renewable resources and load demand

- $0<|E M R| \leq 0.49$ Weak relationship between energy from renewable resources and load demand

- $\quad|\mathrm{EMR}|=0$ No linear relationship between energy from renewable resources and load demand

\subsection{System constraints}

The objective functions formulated in the foregoing subsection are subjected to technical constraints that are needed to meet in order to generate feasible solutions to the problem. The following constraints are considered in the study.

a. The LLPI should be less than or equal to the maximum allowable LLPI as shown in Eqn. (30).

$L L P I \leq \varepsilon_{L L P I}$

b. The EMR should be greater than or equal allowable EMR ratio as shown in Eqn. (31).

$E M R \geq \varepsilon_{E M R}$ 
c. The hourly charge status of the battery is given in Eqn. (32).

$E_{\text {bat }}^{\min } \leq E_{t}^{\text {bat }} \leq E_{\text {bat }}^{\max }$

Where: $E_{b a t}^{\min }, E_{t}^{\text {bat }}, E_{\text {bat }}^{\max }$ are minimum state of charge, present state of charge and maximum state of charge of the battery respectively.

d. Other constraints of the system are given in Eqn (33).

$$
\left\{\begin{array}{c}
0 \leq N_{S H P} \leq N_{S H P}^{\max } \\
0 \leq N_{P V}^{p} \leq N_{P V, \max }^{p} \\
0 \leq N_{b a t}^{p} \leq N_{b a t, \text { max }}^{p}
\end{array}\right.
$$

\section{3. The solution approach}

In the last years, several attempts have been made on the optimal sizing of an HRES by using either optimization or simulation methods. The single objective agenda is the commonest practice that had been implemented by the majorities of researchers in the previous studies in which economic criterion was the most objective considered as the evaluation metric. However, it is of most importance to considered additional criteria like emission effect (if diesel generator is considered as one of the components), reliability investigation and matching of hourly energy production with hourly energy consumption in the design procedure of HRES. Mostly, open literature has shown that there are none or very few studies that simultaneously offer reliability, energy match ratio (EMR) and economic investigation by incorporating operating reserve for an HRES design. Furthermore, several of the reported optimization approaches in the literature are applied to design a building/certain areas energy supply system with renewable energy ratio (RER) of 100\% but, they did not find the best configuration between system cost of energy, reliability and EMR. In general, the major idea of this work is to propose an optimal sizing approach to practically harness the full potential of the renewable energy resources. The employed solution tool adopts simulation-based optimization approaches to acquire the most favourable combination of the examined HRES components.

The design problem has been expressed as a nonlinear constrained MOO problem while a simulationbased Multi-Objective Particle Swarm Optimization method is used to tackle the formulated problem. Using simulation modelling, all systems features and imprecisions can be confined precisely in comparison with other modelling techniques (Sharafi \& ELMekkawy 2014). Nevertheless, simulation is not capable to be used as an independent tool to generate an optimal design of the system. As an, alternative, optimization techniques required a clear mathematical description of the system. A complex system required a complex task when formulating a mathematical model since, there is this possibility that the studied system has a high dimensional space. Consequently, hybridizing simulation model with an optimization approach will overwhelm their limitations. In other words, it will enable the modelling of the complex features of the system and also returning the optimal solution in realistic time.
The first step of the proposed MOO sizing technique for a Hybrid Energy System comprises of a simulation procedure to investigate in case a certain configuration, containing a particular number of each of the system components, meets up with the load demand requirements for the period of one year. The time series hourly data for water discharge, solar irradiation and required load demand of the case study are used to simulate the system hourly.

The PSO algorithm will accommodate the constraints, decision variables and the fitness. Each particle stands for a prospective solution to the optimization problem. LCOE that is specified by the design variables is considered as the fitness of particles for evaluation. In addition, the individual particle randomly produced should fulfil the constraints of the model. After initialization of population of particles by PSO, every particle was sent to the simulation module to review its practicality. The simulation model was run for the period of one year in order to examine the performance of each particle. $L L P I$ and $E M R$ were calculated in the simulation module for the HES. Thereafter, the values of EMR and LLPI are fed back to the optimization algorithm to review if the particle fulfils the constraints otherwise it will be adjusted and fed back to the simulation module to reexamine its practicality.

The second step involves an approach utilizing PSO, which vigorously quests for the system configuration that minimizes the system $L C O E$ and $L L P I$, but maximizes $E M R$ when subject to the condition set in the preceding step. The other vital input for the system optimization are the capital costs per unit, replacement costs per unit, operation and maintenance costs per unit of each component. The feasible particles, after initialization will then be assessed in the PSO algorithms according to their fitness. A stopping condition will then be applied, but, if it is not satisfied, each particle is updated for the next generation in the context of the PSO algorithm. Thereafter, the particles will then be fed back to the simulation module for reconsideration of their feasibility. Then, the simulation outcome will be fed back to the optimization algorithm for assessment. This chain will be concluded once the stopping criterion has been satisfied. After terminating the cycle and all system's component combinations have been sized optimally as explained above, then the combination with the minimum $L C O E$, $L L P I$ and highest EMR will then be displayed as the overall optimal result. The block diagram depicting the proposed approach is represented in Fig. 3. The flowchart of algorithm simulating the hourly operation of the system is shown in Fig. 4.

\section{3.1 Simulation of the system operation}

Combine dispatch strategy which is based on battery charging and discharging strategies was used for an hourly simulation for the 8760 time steps. The dispatch strategy is a control algorithm for the interaction among various system components. The main requirements of the proposed power management strategy for the HES are to meet up with the varying load demand under variable weather conditions and to manage the power flow while ensuring efficient operation of the different energy systems. The control system is necessary for the selection of energy source, monitoring of battery working level and protections of the components. 


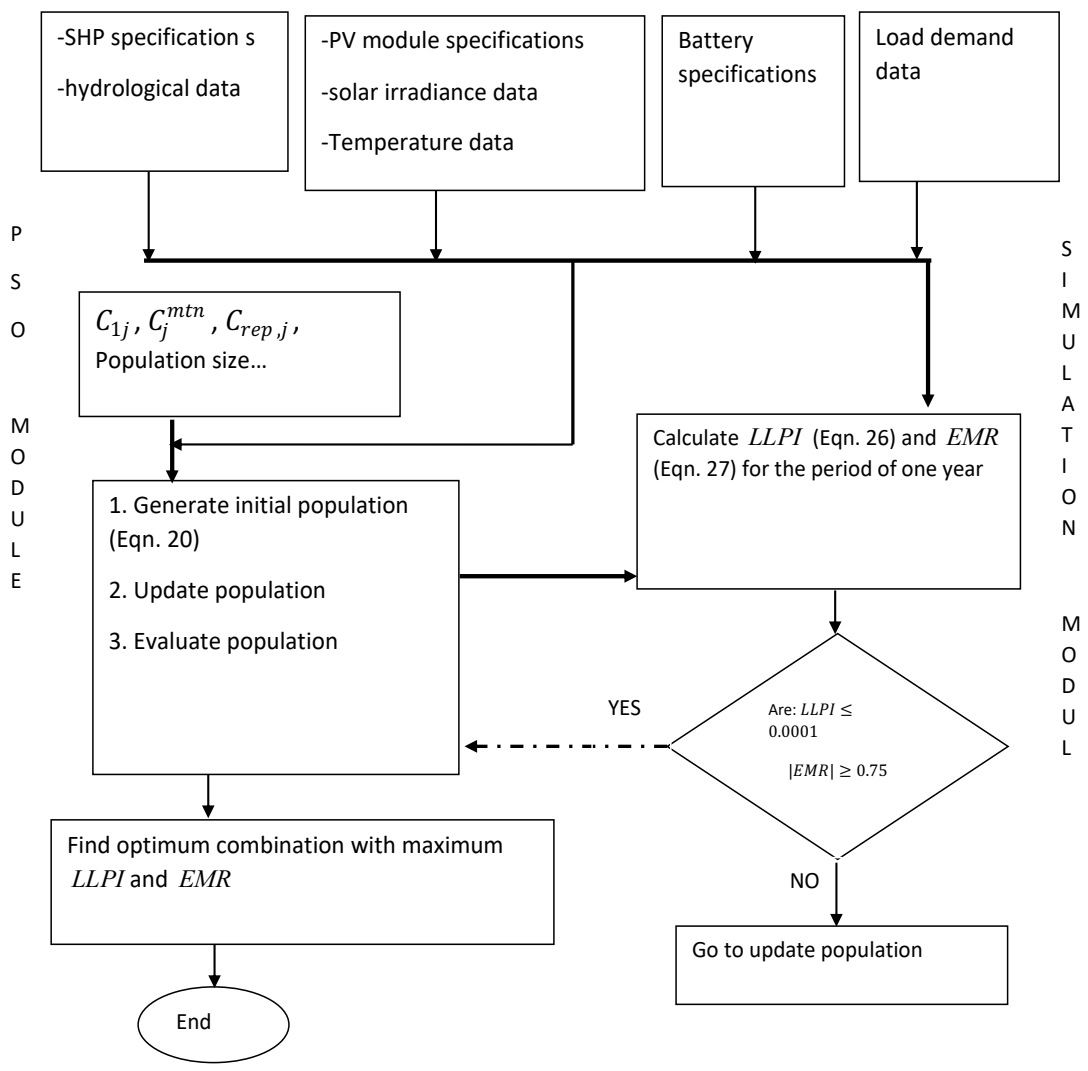

Fig. 3 The proposed simulation-based optimization approach

Table 1

The PSO parameters used for the study

\begin{tabular}{cc} 
Parameter & Value \\
\hline Cognitive constant $\left(\boldsymbol{c}_{\mathbf{1}}\right)$ & 2 \\
Social constant $\left(\boldsymbol{c}_{\mathbf{2}}\right)$ & 2 \\
Maximum number of iteration $\left(\boldsymbol{k}_{\max }\right)$ & 20 \\
Population size & 50 \\
Maximum inertial weight factor $\left(\boldsymbol{w}_{\max }\right)$ & 0.9 \\
Minimum inertial factor $\left(\boldsymbol{w}_{\min }\right)$ & 0.2 \\
Inertial weight factor $(\boldsymbol{w})$ & $w=w_{\max }-\frac{w_{\max }-w_{\min }}{k_{\text {max }}} \times N_{k}$ \\
\end{tabular}

\subsubsection{Optimization approaches}

\subsubsection{Particle swarm optimization algorithm}

PSO is a swarm intelligence which belongs to a class of algorithm called meta-heuristic. It is a technique that was demonstrated by Kennedy and Eberhart in year 1995 (Lan et al. 2015; Coello 2007; Kennedy \& Eberhart 1995; Eberhart \& Kennedy 1995; Kaveh et al. 2013). The Particle Swarm Optimization method (PSO) is majorly employed to address an optimization problem by virtue of its numerous benefits above the other methods, particularly for achieving the minimum Levelized Cost of
Energy (LCE) with a satisfactory range of the production paying attention to the losses between the generation and demand sides; the optimization problem which comprises of objective functions and constraints is formulated taking in consideration fitness values sensitivity in particle swarm process. The outcome of the simulation runs confirmed that PSO is the encouraging optimization method owing to its capability to attain the global optimum with relative simplicity and computational proficiency contrasted with the customary optimization methods. Metaheuristics may not assure that a globally best result can be obtained on some class of problems. In 
PSO, a group of particles called swarm is produced haphazardly. Every single particle in the population is a possible answer to the optimization problem. The $i^{\text {th }}$ likely solution in the population can be denoted by a Ddimensional vector, $X_{i}=\left(x_{i 1}, x_{i 2}, \ldots, x_{i D}\right)^{T}$. Likewise, the velocity can be characterized by additional $D$-dimensional vector $V_{i}=\left(v_{i 1}, v_{i 2}, \ldots, v_{i D}\right)^{T}$. The previously best position visited by this $i^{\text {th }}$ particle is given by $P_{i}=$ $\left(p_{i 1}, p_{i 2}, \ldots, p_{i D}\right)^{T}$, if $g$ represents the index of the best particle in the population and superscripts $k$ stands for the iteration integer. The swarm is updated based on the Eqns. (34) -(35).

$x_{i d}^{k+1}=x_{i d}^{k}+\Delta t v_{i d}^{k+1}$

$v_{i d}^{k+1}=w * v_{i d}^{k}+c_{1} * r_{1}^{k} *\left(p_{i d}^{k}-x_{i d}^{k}\right) / \Delta t+c_{2} * r_{2}^{k} *\left(p_{g d}^{k}-\right.$ $\left.x_{i d}^{k}\right) / \Delta t$

where:

- $d=1,2,3, \ldots D ; i=1,2,3, \ldots N \quad N$ is the size of the swarm,

- $w$ is the inertia weight,

- $\Delta t$ is the time step,

- $\quad c_{1}$ and $c_{2}$ are "self-confidence" and "swarm confidence" respectively,

- $\quad r_{1}$ and $r_{2}$ are random numbers, evenly distributed in $[0,1]$, and

- $\quad \mathrm{k}$ is iteration number.

The first iteration will be ended after modifying the positions and velocities for the subsequent time step $(k+$ 1 ). Coherently, the process will be executed continuously till when a determined stopping criterion is accomplished. The critical parameters required for PSO algorithm are swarm size, $\omega$, cognitive and social parameters $c_{1}, c_{2}$. These are the required parameters needed to be initialized by the users before the beginning of execution. Based on the literature survey, the appropriate values for these parameters are presented in Table 1.

\subsubsection{The $\varepsilon$-constraint method}

The $\varepsilon$-constraint technique is a simple multi-objective optimization approach that can be used simply by selecting one objective to be optimized and the additional ones are regarded as constraints bound by defining target levels $\left(\varepsilon_{i}\right)$ (Sharafi \& ELMekkawy 2014). As the target levels are being varied, the non-dominated solutions of the optimization problem can be determined. Considering the MOP as shown in Eqn. (36):

$\operatorname{Min}\left\{f_{1}(x), f_{2}(x), \ldots f_{k}(x)\right\}$

where, $x$ is decision vector, $f_{i}(i=1,2, \ldots k)$ represent the criteria. A given solution $x^{*}$ is supposed to be a nondominated solution if there is no any other possible solution $x$ such that $f_{i}(x) \leq f_{i}\left(x^{*}\right)$ for all $i=1,2, \ldots k$ and at least one inequality is strict. Considering the $\varepsilon$ constraint approach, if $f_{j}(x), j \in\{1,2, \ldots k\}$ is the criterion preferred to be optimized, and $f_{i}(x)$ is the objective selected as the constraint (Sharafi \& ELMekkawy 2014).

$\operatorname{Min} f_{j}(x) \quad j \in\{1, \ldots, k\}$

Subject to

$f_{i}(x) \leq \varepsilon_{i} \quad \forall i \in\{1, \ldots, k\}, i \neq j, x \in S$

where $S$ is the solution space. $L C O E$ is selected as the objective function to be optimized while $L L P I$ and $E M R$ are integrated as inequality constraints in the modes: $L L P I \leq \varepsilon_{L L P}$ and $E M R \geq \varepsilon_{E M R}$.

\subsection{Description of case study and data acquisition}

Nigeria has an enormous potential for renewable energy which still remains largely unused. Virtually all the regions in the country are blessed with sufficient renewable energy resources which can satisfy energy need of the country if it is economically and properly harnessed. The remarkable sources are solar energy, biomass, geothermal, wind, hydropower, hydrokinetic energies among others. The average solar irradiance in the country falls between $3.5-7.0 \mathrm{kWh} / \mathrm{m}^{2} /$ day, while the wind speed ranges from $2-4 \mathrm{~m} / \mathrm{s}$ at $10 \mathrm{~m}$ height, as recognized small hydropower has a potential of 735 MW (Sambo 2009). Akuru et al. (2017) emphasize the promising renewable energy sources which are vital to solve the persistent problem of electricity generation in Nigeria. It was recommended that individuals can take the lead in driving the evolution from traditional based electricity generation to $100 \%$ renewable energy rather than reliance on government always.

The ten-year hourly electricity load profile is estimated for the cluster of the three communities in Nigeria using the end-use modelling technique as presented in Figs. 5(a) and (b) for the dry and rainy seasons respectively. Also, the hourly water discharge of the river under consideration was estimated by installing a water gauge station at a determined location to gauge the daily water level for one year. The correlation between measured velocity and the geometry of the channel was used to transform water gauges to discharges as shown in Fig. 6. Flow probe with model number FP211 was used to measure the velocity of the water whereas the Digital Elevation Model (DEM) was utilized to indicate the proposed locations of diversion weir, forebay and power house in order to determine the net head. The hourly solar irradiance and temperature data for year for ten years were acquired from the Nigeria Meteorological Station, Ilorin International Airport, as presented in Figs. 7 and 8 respectively. Techno-economic data for all components considered are represented in Tables 2 to 4 . The small hydropower energy, load demand and solar energy are considered to be invariable during a time-step of 1 hour and the system DC bus voltage has a value of 240 volts. 


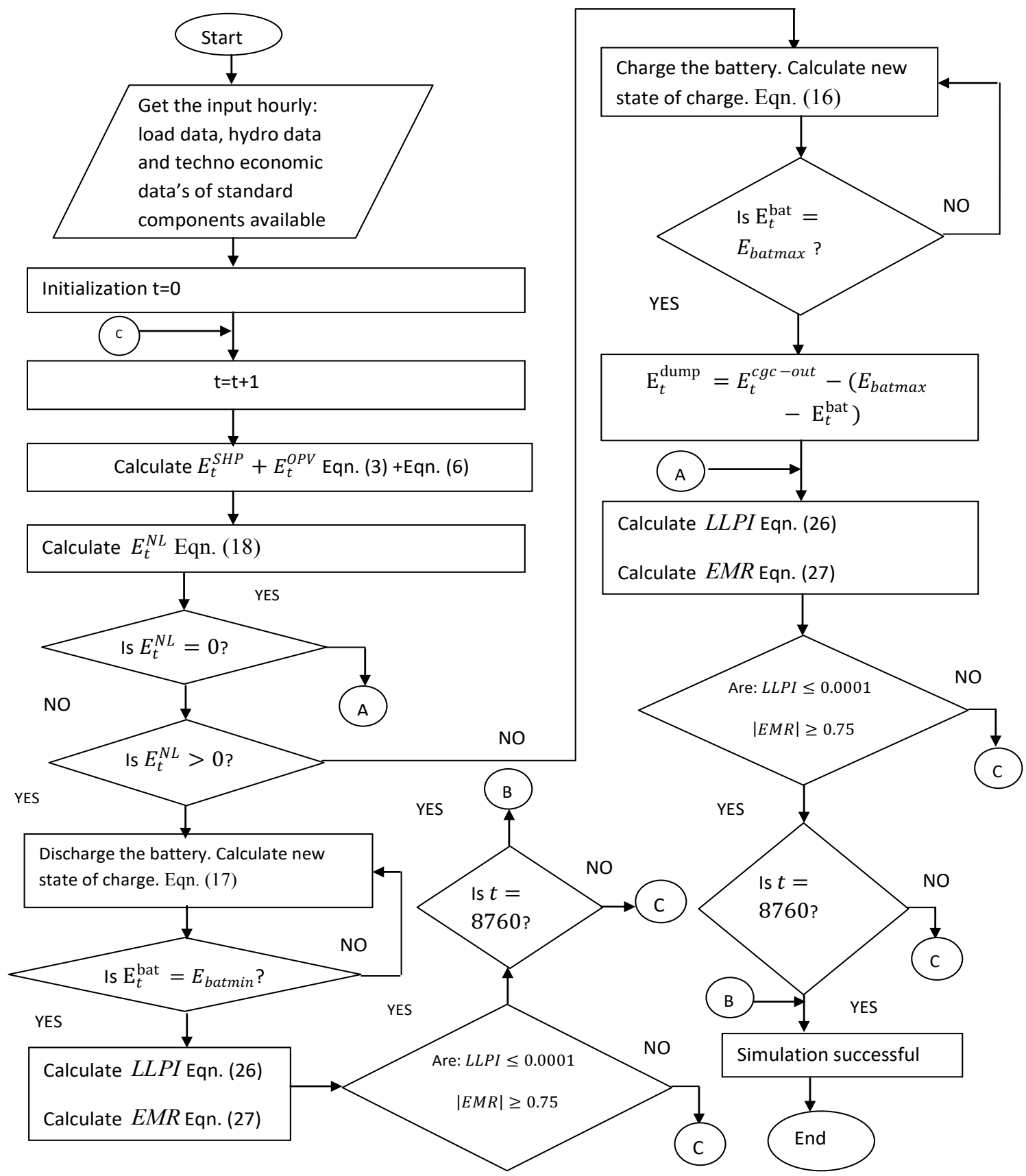

Fig.4 Flowchart of the Algorithm Simulating the Dispatch Strategy using $\varepsilon$-Constraint Method.

Table 2

Technical Specifications and the Capital Costs of a Sharp Solar PV modules

\begin{tabular}{cc} 
System parameters & Values \\
\hline Rated power per unit $\left(\boldsymbol{P}_{\boldsymbol{N}-\boldsymbol{P V}}\right)(\mathrm{W})$ & 200 \\
Rated voltage $\left(\boldsymbol{V}_{\boldsymbol{P V}}\right)(\mathrm{V})$ & 24 \\
Maximum power voltage $(\mathrm{V})$ & 36.5 \\
Cost per unit (\$) & 115.52 \\
BOS Cost (50\% of unit cost) (\$) & 57.76 \\
Capital cost per unit $\left(\boldsymbol{C}_{\boldsymbol{I}, \boldsymbol{P V}}\right)(\$)$ & 173.28 \\
Lifespan of the module (years) & 25 \\
\hline
\end{tabular}




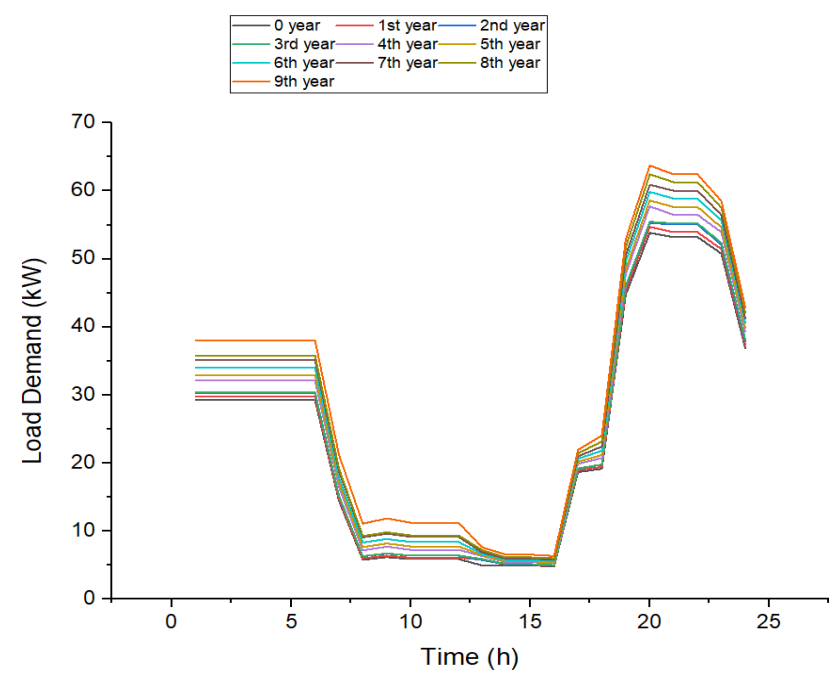

(a)

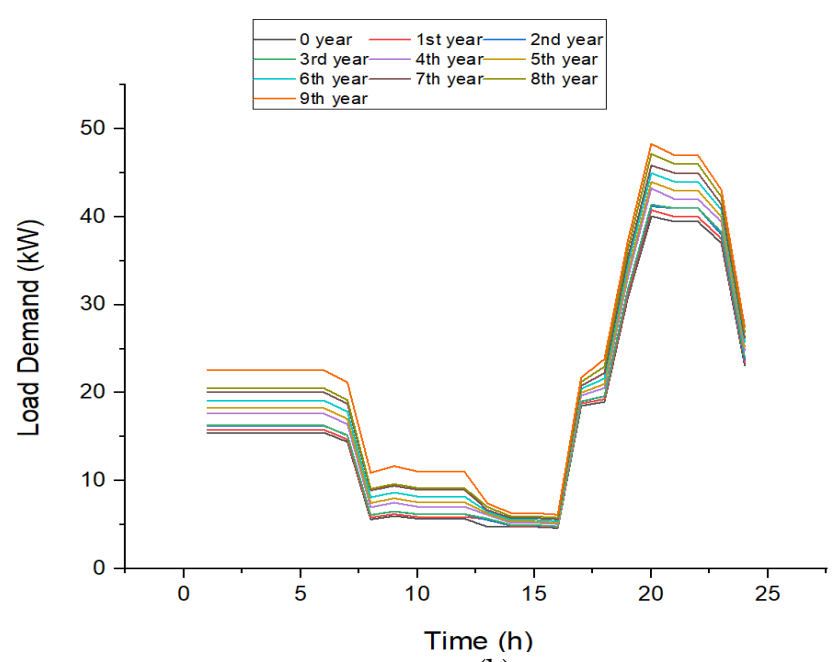

(b)

Fig. 5(a) and b Ten-year forecasted hourly load demand for the dry season (November - April) and rainy season (May-October)

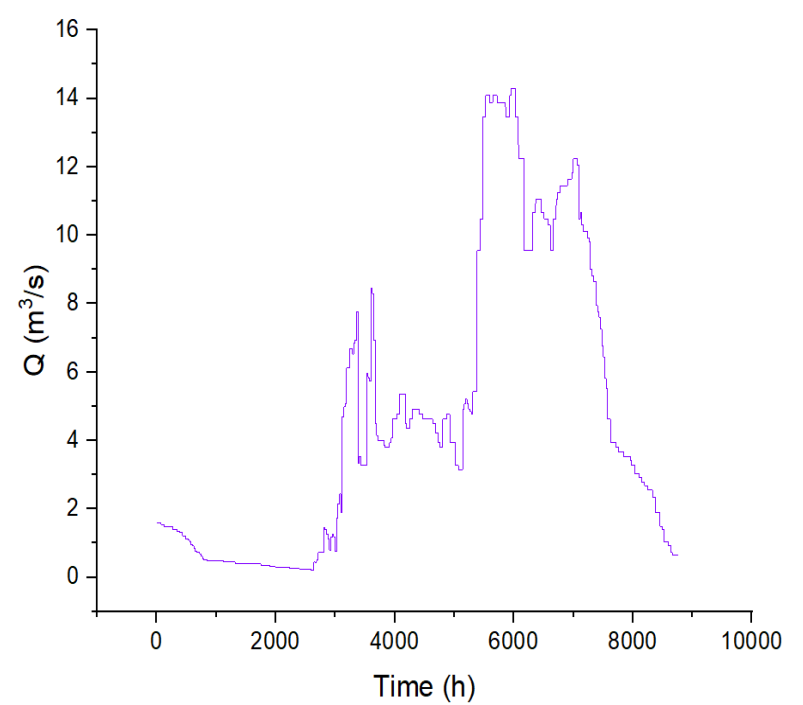

Fig. 6 Hourly variation of discharge in the river for one year (January - December, 2017)

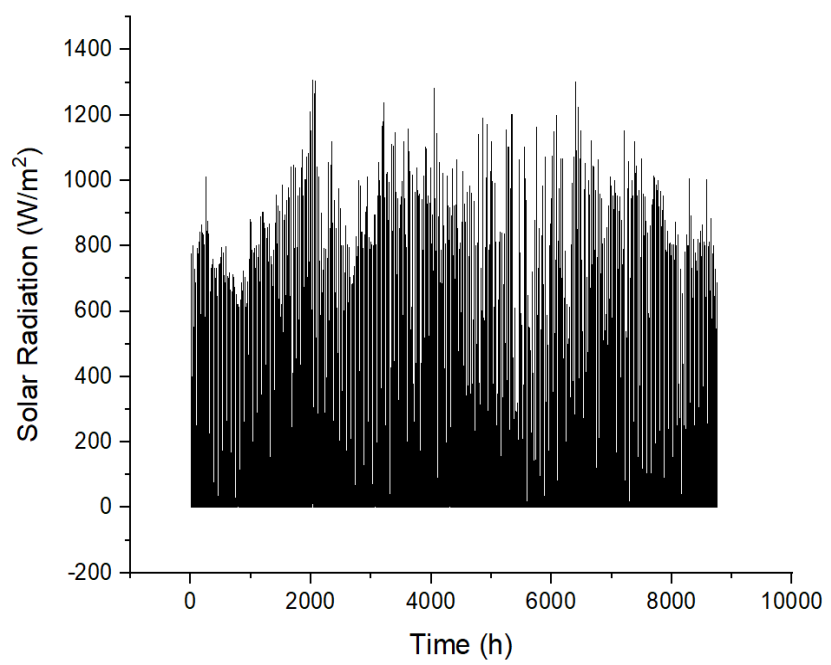

Fig. 7 Average hourly solar insolation data (2010-2016).

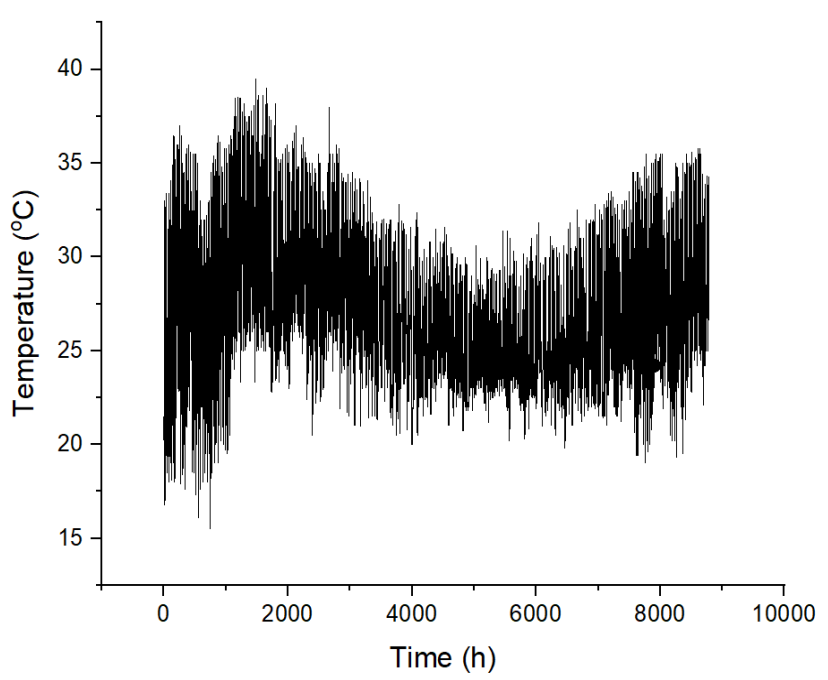

Fig. 8 Average hourly temperature data (2010-2016)

Table 3

Technical specifications and the capital costs of the energy storage system

\begin{tabular}{lc}
\hline System parameters & Values \\
\hline Ah per battery & 100 \\
Voltage per battery $\left(\boldsymbol{V}_{\boldsymbol{n}}\right)(\mathrm{V})$ & 12 \\
Energy size of each battery $\left[\boldsymbol{E}_{\boldsymbol{n}}=\left(\boldsymbol{V}_{\boldsymbol{n}} \times \boldsymbol{A h} /\right.\right.$ & 1.2 \\
$\mathbf{1 0 0 0})]$ & \\
Cost per unit (\$) & 206.28 \\
BOS Cost (2\% of unit cost) $(\$)$ & 4.13 \\
Capital cost per unit $\left(\boldsymbol{C}_{\boldsymbol{I}, \boldsymbol{b a t}}\right)$ of battery $(\$)$ & 210.41 \\
Replacement cost per battery $\left(\boldsymbol{C}_{\boldsymbol{r e p}, \boldsymbol{b a t}}\right)(\$)$ & 206.28 \\
Charging efficiency & 0.89 \\
Discharging efficiency & 1.00 \\
Lifespan (years) & 4 \\
\hline
\end{tabular}


Table 4

Other parameters

\begin{tabular}{|c|c|}
\hline Description & Data \\
\hline \multicolumn{2}{|l|}{ PV Regulator } \\
\hline Efficiency of PV regulator & 0.95 \\
\hline PV regulator cost & 2000US $\$$ \\
\hline \multicolumn{2}{|c|}{$\begin{array}{l}\text { GL760-LM-40 Small Hydropower Generating System (Kaplan turbine and permanent magnet } \\
\text { generator complete set) }\end{array}$} \\
\hline Capital cost per unit $\left(\boldsymbol{C}_{I, S H P}\right)$ (Maria et al., 2017) & $62,000 \mathrm{US} \$$ \\
\hline Efficiency of turbine $\left(\boldsymbol{\eta}_{t u}\right)$ & $91 \%$ \\
\hline Efficiency of generator $\left(\boldsymbol{\eta}_{g}\right)$ & $95 \%$ \\
\hline Net Head $\left(\boldsymbol{H}_{\boldsymbol{n}}\right)$ & $7.63 \mathrm{~m}$ \\
\hline Gross head $(\boldsymbol{H})$ & $8 \mathrm{~m}$ \\
\hline Discharge $\left(\boldsymbol{Q}_{b}\right)$ & $0.8 \mathrm{~m}^{3} / \mathrm{s}$ \\
\hline \multicolumn{2}{|c|}{ BZP 50kW 240V DC battery input hybrid inverter with 3-phase output } \\
\hline Efficiency & 0.92 \\
\hline Life span & 25 years \\
\hline Capital cost $\left(\boldsymbol{C}_{\text {Iinv }}\right)$ & 8000 US $\$$ \\
\hline Input DC bus voltage $\left(\boldsymbol{V}_{\text {bus }}\right)$ & 240V DC \\
\hline \multicolumn{2}{|l|}{ Economic parameters } \\
\hline Nominal interest rate ir (\%) (CBN, 2017) & 14 \\
\hline Inflation rate $f(\%)(\mathrm{CBN}, 2017)$ & 15.4 \\
\hline \multicolumn{2}{|l|}{ Operating Reserve } \\
\hline Load $(\% \mathrm{~L})$ & $10 \%$ of $E_{t}^{L}$ \\
\hline $\mathrm{PV}(\% \mathrm{PV})$ & $20 \%$ of $E_{t}^{P V}$ \\
\hline
\end{tabular}

Table 5

Optimal size of components for scenarios 1 to 4

\begin{tabular}{|c|c|c|c|c|c|c|c|c|}
\hline \multirow[b]{2}{*}{ Scenarios } & \multicolumn{5}{|c|}{ Number of Components } & \multicolumn{3}{|c|}{ Values of Objective Functions } \\
\hline & $N_{\text {bat }}$ & $N_{P V}$ & $N_{S H P}$ & $N_{b a t}^{p}$ & $N_{P V}^{p}$ & $\operatorname{LCOE}(\$)$ & $L L P I$ & $|E M R|$ \\
\hline 1 & 40 & 570 & 4 & 2 & 57 & 0.41739 & 0.00004731 & 0.75 \\
\hline 2 & 40 & 640 & 5 & 2 & 64 & 0.41724 & 0.00009851 & 0.75 \\
\hline 3 & 40 & 640 & 5 & 2 & 64 & 0.41718 & 0.00009851 & 0.75 \\
\hline 4 & 40 & 770 & 2 & 5 & 77 & 0.417 & 0.00007921 & 0.75 \\
\hline
\end{tabular}

\section{Results and Discussion}

\subsection{Solution approach}

The solution approach is implemented in MATLAB programming setting in a $2.3 \mathrm{GHz}$ dual core processor. It is implemented to design a hybrid energy systems comprising of small hydropower/PV panels/batteries to generate electricity for the group of three un-electrified off-grid rural settlements located in North Central Region, Nigeria. Since a hybrid energy system usually lasts more than 5 years, the projected $10^{\text {th }}$ year annual load profile is used. The optimal solution produced by the proposed $\varepsilon$ constraint approach is given in Table 5. In this table, the best founded result is shown as the minimum LCOE and LLPI, and maximum EMR for the allowable values of LLPI and EMR as $\$ 0.41739 / \mathrm{kWh}, 0.00004731$ and 0.75 respectively.

In order to explore how possible change of the capacity per unit of input parameters may influence the optimal solution produced by the optimization algorithm under a specific number of assumptions, three Scenarios were considered. They are 130 Ah battery with $250 \mathrm{Wp}$ PV for Scenario 2, 150 Ah battery with $280 \mathrm{Wp} \mathrm{PV} \mathrm{for}$ Scenario 3 and 200 ah with $300 \mathrm{Wp}$ PV for Scenario 4. The capital cost per unit of solar PV for Scenarios 2 to 4 are $\$ 127.89 /$ unit, $\$ 156.77 /$ unit and $\$ 169.15 /$ unit respectively. Also, the capital cost and replacement cost per unit of battery for Scenario 2 to 4 are $\$ 241.27 /$ unit and \$236.54/unit, \$263.71/unit and \$258.54/unit, \$392.76/unit and $\$ 385.06 /$ unit respectively. The results of Scenarios 2 to 4 are also presented in Table 5. For all the Scenarios considered, it is observed that a minimum of two number of small hydropower is considered to meet up with the hourly load demand. Scenario 1 which has the lower capacity per unit of PV and battery has the highest $L C O E$ given as $\$ 0.41739 / \mathrm{kWh}$ for $L L P I \leq 0.0001$ and $R^{E M} \geq 0.75$ while Scenario 4 with highest capacity per unit of PV and battery has the lowest $L C O E$ given as $\$ 0.417 / \mathrm{kWh}$ for $L L P I \leq 0.0001$ and $E M R \geq 0.75$.

The percentage of contribution of individual component to the overall energy supply systems in the ninth year over one year for Scenarios 1 to 4 using the proposed approach is represented in Fig. 9. The percentage of participation of solar PV is the highest in all the scenarios considered followed by the small hydropower and lastly the battery banks. This implies that the peak sun hours (PSH) which is defined as the duration in hours at $1 \mathrm{~kW} / \mathrm{m}^{2}$ insolation level needed to produce energy that is corresponding to the overall energy per day for the location is greater than 3. The contribution of solar PV and small hydropower in Scenarios 1 to 4 are $92 \%, 92 \%, 94 \%$, $95 \%$ and $7 \%, 7 \%, 6 \%, 5 \%$ respectively. Scenario 4 with the lowest $L C O E$ has the highest percentage of solar PV contribution and the lowest small hydropower contribution. This further implies from Fig. 9 as shown from Scenarios 1 to 4 that the cost of energy for PV is 
cheaper as compared to that of small hydropower. The outcome also shows little contribution of battery energy storage system as shown in Fig. 9 for all the Scenarios. One major reason for this low contribution can be as a result of the incorporation of hourly spinning operating reserve and high cost of battery. In short, Solar PV production has a substantial effect on the storage capacity and the small hydropower production as it contributed highest power hourly for all the Scenarios as shown in Fig. 10 (a)-(d). The capacity of the components as evident in Tables 5 and 6 is enough to meet up with the hourly electrical load demand.

\subsection{Validation of results with HOMER software}

The same set of input data was utilized to implement the multi-objective optimization problem with HOMER optimization software. Different configuration schemes of the proposed hybrid energy systems are displayed in Fig. 11 as the output results of HOMER are represented in Table 6. It can be observed in the table that the small hydropower was selected in each of the scenarios throughout the year. The $L C O E$ for Scenarios 1 - 4 were found to be $\$ 0.777 / \mathrm{kWh}, \quad \$ 0.420 / \mathrm{kWh}, \quad \$ 0.43 / \mathrm{kWh}$, $\$ 0.444 / \mathrm{kWh}$. The Scenario 1 which has the lowest capacity per unit of PV and battery has the highest $L C O E$ while Scenario 2 which also has the lower capacity of PV and battery has the lowest $L C O E$

\section{Scenario 1}

\section{PV
SMALLHYDROPOWER
BATTERY}

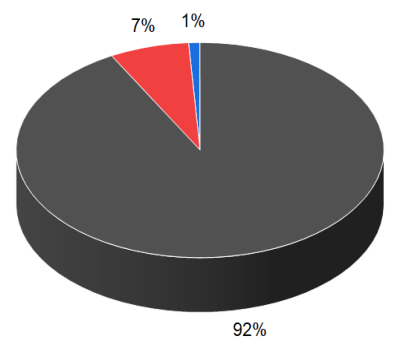

Scenario 3

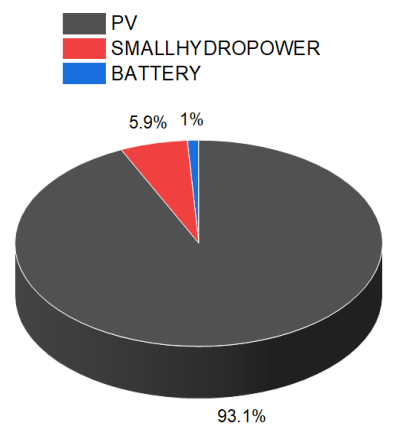

Fig. 9 Percentage contribution of each component to the overall energy supply

Scenario 4

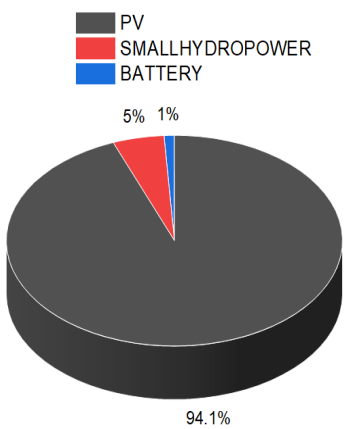

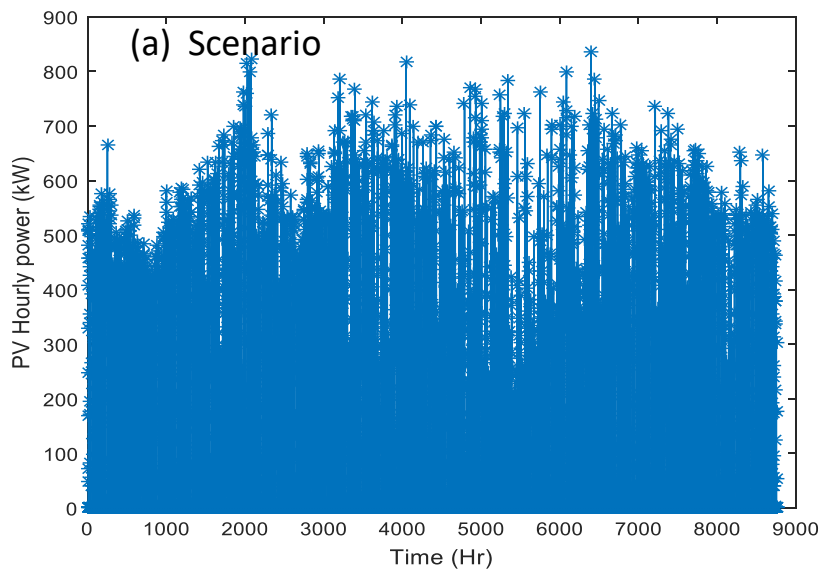
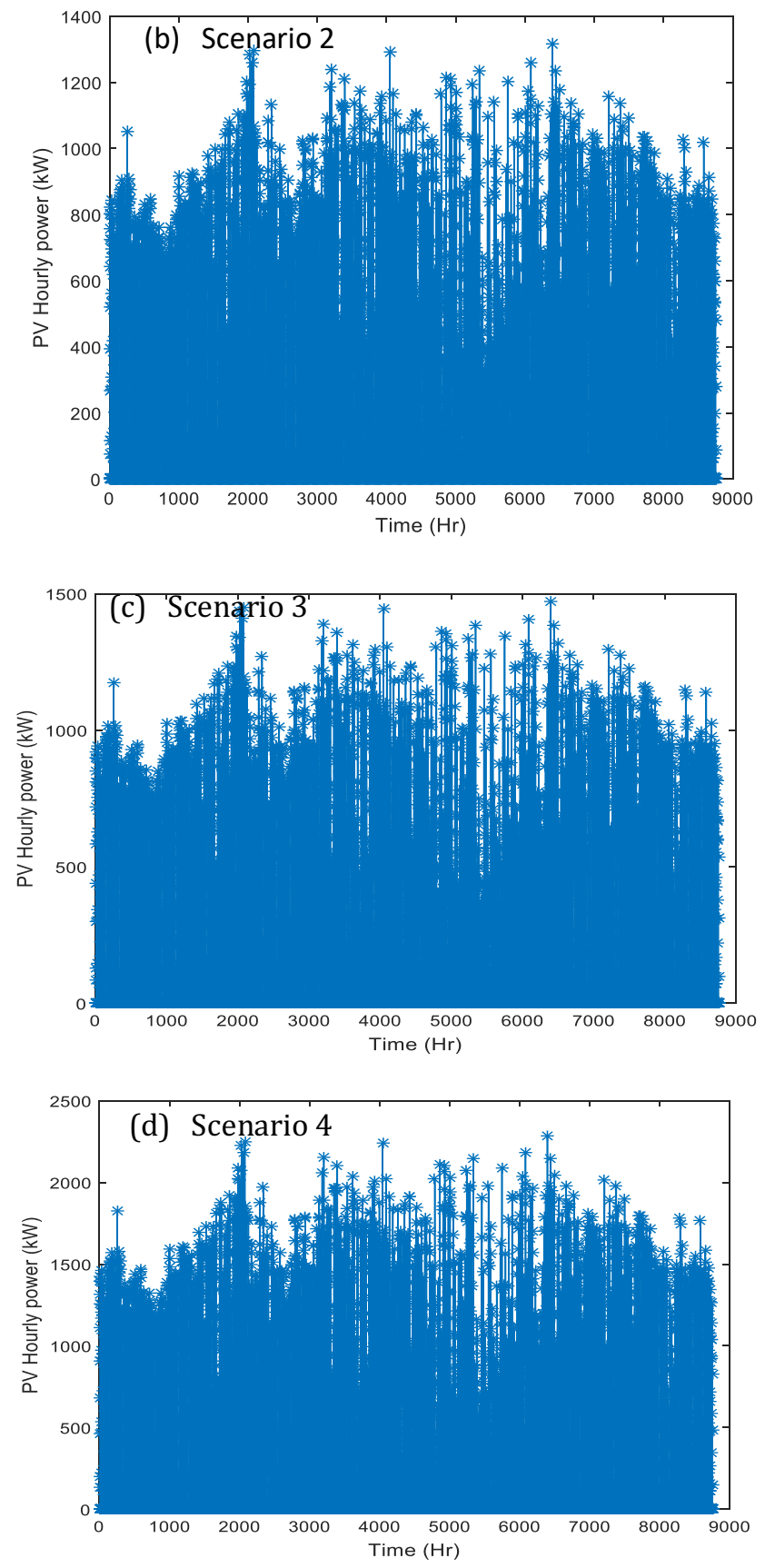

Fig. 10 (a)-(d) Hourly power contribution of Solar PV for Scenarios 1-4 


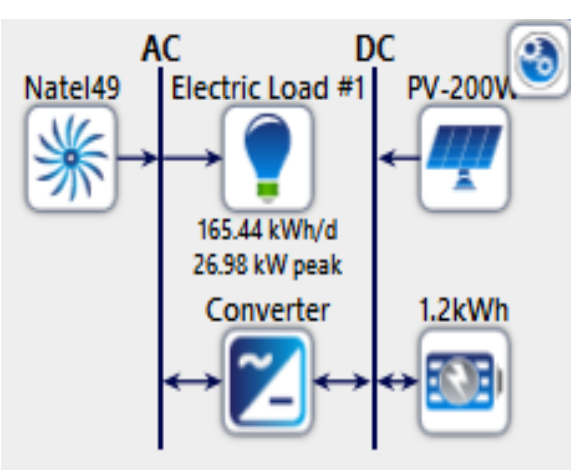

Scenario 1

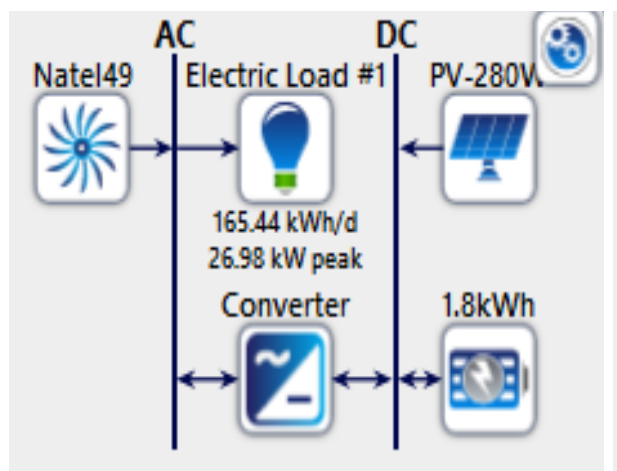

Scenario 3

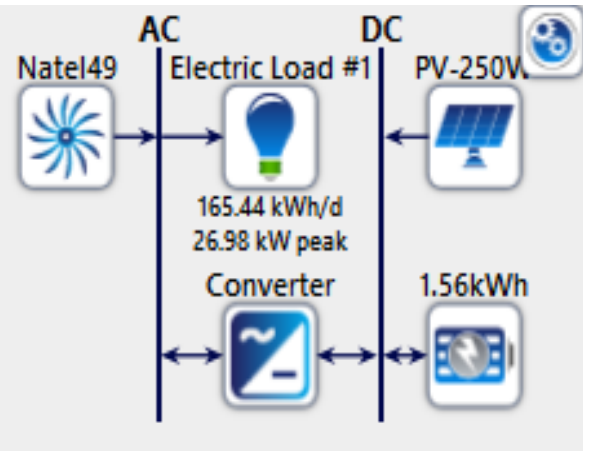

Scenario 2

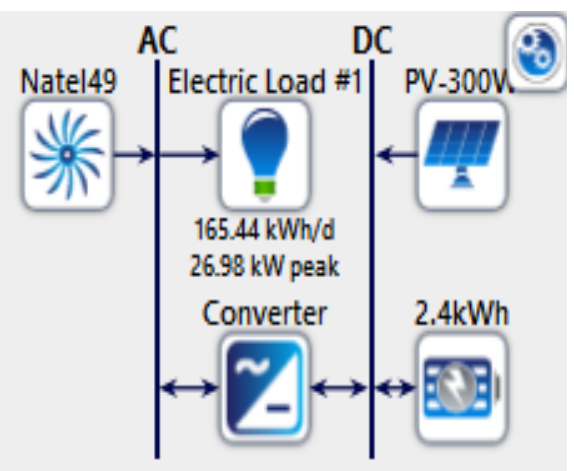

Scenario 4

Fig. 11 Different scenarios of hybrid energy system simulated in HOMER software

Table 6

Optimal size of components using HOMER for scenarios 1 to 4

\begin{tabular}{|c|c|c|c|c|c|c|c|}
\hline \multirow{2}{*}{ Scenarios } & \multicolumn{5}{|c|}{ Capacity of Components } & \multicolumn{2}{|c|}{ Values of Objective Functions } \\
\hline & $N_{\text {bat }}$ & $P_{P V}(\mathrm{~kW})$ & $P_{S H P}(\mathrm{~kW})$ & $N_{\text {hat }}^{p}$ & $P_{\text {inv }}(\mathbf{k W})$ & $\operatorname{LCOE}(\$)$ & LLPI \\
\hline 1 & 960 & 142 & 206 & 48 & 28.80 & 0.777 & 0.00083 \\
\hline 2 & 540 & 162 & 206 & 27 & 33.50 & 0.420 & 0.000898 \\
\hline 3 & 720 & 119 & 206 & 36 & 35.2 & 0.43 & 0.000827 \\
\hline 4 & 360 & 162 & 206 & 18 & 33.9 & 0.444 & 0.000880 \\
\hline
\end{tabular}

\subsection{Comparison of results}

Both the proposed and Homer optimization methods were presented and tested using the same input data. The hourly performance simulation of the components of the hybrid renewable energy system is calculated under "the combined dispatch strategies" i.e battery charging and discharging strategies. The economic results of the system from HOMER system are described in Table 4. The cost of the PV subsystem is the leading cost as a result of its highest hourly power contribution from the overall energy mix followed by the small hydropower and lastly the battery bank in both cases. The comparative investigation shows that the optimal configuration of the proposed methodology is more cost effective than HOMER system. The levelized cost of energy is $0.417 \$ / \mathrm{kWh}$ for the simulation-based optimization approach combined with $\varepsilon$ constraint method and $0.444 \$ / \mathrm{kWh}$ for HOMER. It is also found that the proposed optimization approach has lower LLPI than HOMER system. Homer does not consider the number of units of generating sources rather it considers the capacity in $\mathrm{kW}$ which increases the annual excess electricity generation.

Homer can determine renewable energy ratio but it cannot maximize coincidence of hourly load profile to demand profile so as to minimize the participation of energy storage. Homer also lacks flexibility in setting up of constraints. HOMER does not consider the effect of DOD of the battery which has a significant role in lifetime of the battery bank.

\subsection{Environmental benefits}

Literature has established that the fossil fuel-based electricity generation approaches are one of the major sources of anthropogenetic carbon dioxide emissions to the airspace (Azoumah et al. 2011; Ballat \& Ballat 2010). The yearly electrical energy required for the group of the three rural settlements in the base year (0 year) is estimated as $176,713.32 \mathrm{kWh}$ and $229,008.14 \mathrm{kWh}$ in the ninth year using end-use modelling technique. Electrical energy saving for $1 \mathrm{kWh}$ will produce $0.8 \sim 0.9 \mathrm{~kg} \mathrm{CO}$ (Kamal 2012). 


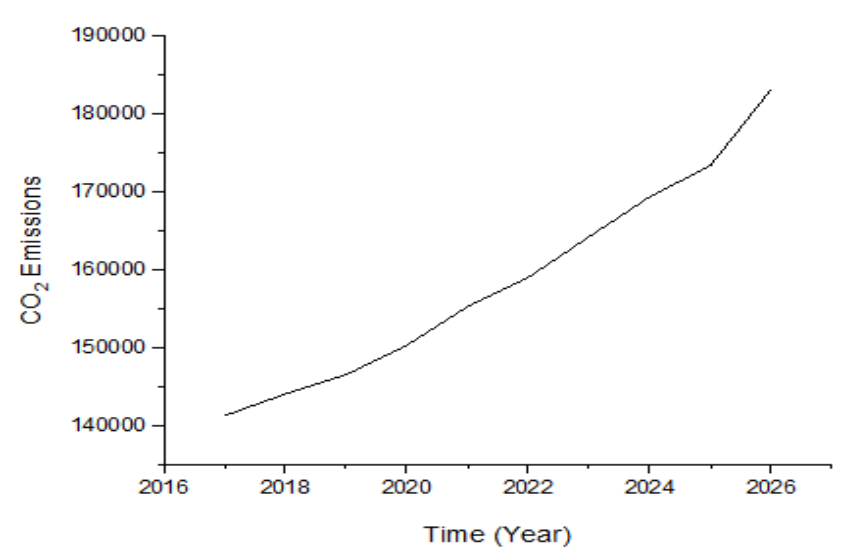

Fig. 12 Estimated annual emissions for 10 years

From environmental perspective, $141,370.66 \mathrm{~kg}$ of $\mathrm{CO}_{2}$ and $183,206.51 \mathrm{~kg}$ of $\mathrm{CO}_{2}$ would be saved in the base and ninth year respectively by using renewable sources as against grid extension to the communities from the nearest gird, which imposes more demand from the central generators. The estimated annual emissions that would, therefore, be saved from the atmosphere, using the renewable resources to supply electricity needs of the proposed rural communities from base year to ninth year are represented in Fig. 12.

\subsection{Carbon credit}

Carbon credit is a certification that is issued to an organization to emit permissibly a definite amount of carbon dioxide and the variation, if available can be negotiated if the full grant is not achieved. In simpler term, the higher the emissions the higher the expenses, and the lower the carbon emissions the higher the credits that can be sold or exchanged. This emission is now becoming a product that helps people, countries, consultants and even farmers to make billions of dollars. For business purposes, one certified emission reduction $(\mathrm{CER})$ is corresponding to one metric ton of $\mathrm{CO}_{2}\left(\mathrm{tCO}_{2}\right)$ emissions. Likewise, based on GEF approximation, 1 MWh will generate $0.8 \mathrm{t}$ of $\mathrm{CO}_{2}$. The CERs can be marketed secretly or in the international market at the normal market worth. At the moment the worth for carbon emissions is $\$ 9.90 / \mathrm{t}$ of $\mathrm{CO}_{2}$, revenue of $\$ 1399.5$ and $\$ 1,813.7$ will be obtained in the base and ninth year respectively as presented in Fig. 13.

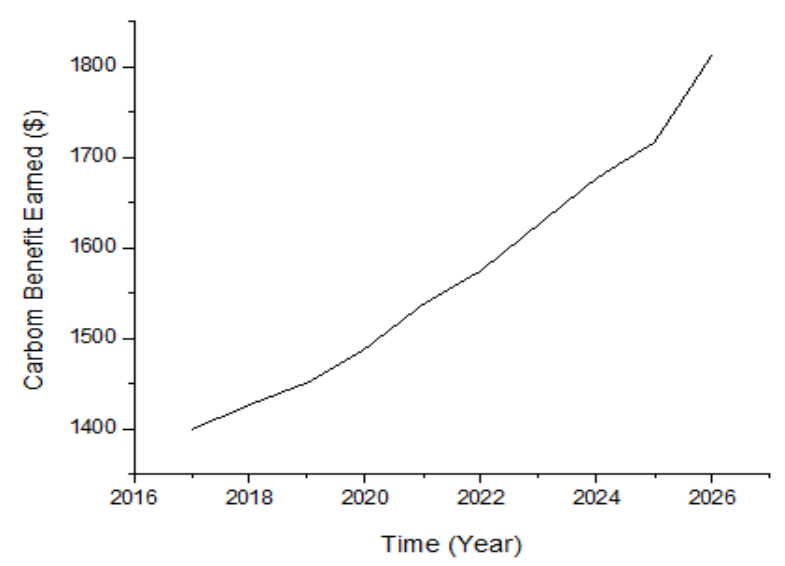

Fig. 13 Carbon benefit earned between base and ninth year.

\section{Conclusion}

In this paper, a unique and simple method is presented to optimize the size of a hybrid renewable energy system. The $\varepsilon$-constraint method has been applied to minimize two objectives namely levelized cost of energy, loss-of-load probability index and to maximize one objective named energy match ratio. The suggested tool used a PSO-based simulation method to solve the formulated multi-objective optimization problem. The primary advantage of the proposed approach is its simplicity which leads to computational efficiency.

The proposed approach was utilized to design a hybrid energy system, which comprised small hydropower, solar PV and battery storage system for a group of three off-grid rural settlements as a case study. The $\varepsilon$-constraint approach was applied under a specific number of assumptions for four different scenarios. The outcomes from the proposed method were validated with those obtained using HOMER optimization software with the same input data set and assumptions. It was found that the proposed approach showed more dynamism and coherence in choosing different components relative to HOMER software. The levelized cost of energy was cheaper with the proposed method than that from HOMER software. Since a basic constraint for the optimization of a hybrid energy system is to continuously satisfy the load request, this was achieved excellently in the proposed approach as the loss-of-load probability index was lower than that obtained from the HOMER software. The proposed approach can be adopted in carrying out viability studies and the design of hybrid energy systems for off-grid rural communities with solar and hydropower potentials in any location on the globe.

The outcomes of these study are briefly listed as follows:(i)Proposing a method based on $\varepsilon$-constraint method for optimal design of HRES including solar photovoltaic system, small hydropower generators and battery energy storage devices, (ii) The beautiful features of this proposed approach are its simplicity and the moderately less computational effort, (iii)Performing a multi-objective optimization methodology to consider a novel energy match ratio as an objective function when optimizing the design of off-grid rural areas electrical energy supply system, (iv) Integrating spinning operating reserve in renewable energy resource and load demand when sizing an off-grid rural areas electrical energy supply system. To be specific, the unpredictability in solar radiation, water flow, temperature and load demand are simultaneously considered in the sizing procedure of HRESs.

The energy generation to the rural communities under study was considered completely as electrical energy, but it may possibly be more effective to divide the load demand into heat and electrical demands and use different approaches to satisfy each. The feasibility of combining other renewable sources of energy such as geothermal and hydrokinetic sources may be considered in future researches. In addition, more optimization criteria to minimize excess electricity generation, maximize system reliability are needed to be considered in future research works. 


\section{Nomenclature}

$E^{A E G}$

CRF

$\eta_{\text {bat }}$

$\eta_{\text {inv }}$

$\eta_{c g c}$

$g$

ir

$c_{1}$

$E_{t-1}^{\text {bat }}$

$c_{2}$

$(D O D)_{\max }$

$T_{a m b}$

$E_{S H P}^{A N}$

$E_{P V}^{A N}$

$i$

$\eta_{d c h}$

$h_{b}$

$\eta_{\text {cha }}$

$C_{\text {rbat }}$

$V_{\text {bus }}$

$\eta_{g}$

$\eta_{t u}$

$\% L$

$P_{t}^{p}$

$E_{t}^{S}$

$E_{t}^{p}$

EMR

$h_{f}$

$H_{g}$

$L D_{t}$

$f$

$k$

LLPI

$C_{P V}^{m t n}$

$C_{S H P}^{m}$

$Q_{\max }$

$Q_{\min }$

$H_{n}$

$V_{P V}$
$N_{\text {bat }}^{p}$

$N_{\text {bat }}$

$D_{A}$

$n_{q r}$

$n_{q r}^{s b y}$

$N_{S H P}$

$N_{P V}$
$N_{P V}^{p}$

$N_{P V}^{p}$
$N_{P V}^{s}$

$R_{\text {bat }}$

$h_{o}$

$C_{I, \text { bat }}$

$C_{I, c g c}$

$C_{I, S H P}$

$C_{I, P V}$

$P_{q r}$
Annual energy generated from all the sources

Capital recovery factor

Efficiency of battery

Efficiency of inverter

Efficiency of the charge controller

Index of the best particle in the population

(swarm)

Nominal interest rate

Self-confidence

State-of-charge of the battery at time t-1

Swarm confidence

Maximum depth-of-discharge of battery bank Ambient temperature

Annual energy generated from total number of hydropower generating unit

Annual energy production from the total

number of solar modules

Annual interest rate

Battery discharging efficiency

Bend losses

Battery bank charging efficiency

Per unit battery replacement cost

DC bus voltage

Efficiency of the generator

Efficiency of the turbine

Electrical load operating reserve

Electrical power generated at time t by a

single PV panel

Energy generated by a single small

hydropower generating unit

Energy generated by a single solar PV

Energy Match Ratio

Frictional losses

Gross head

Hourly electrical loads $\left(L D_{t}\right)$

Inflation rate

Iteration number

Loss-of-load probability index

Maintenance cost per $\mathrm{kWh}$ for PV

Maintenance cost per $\mathrm{kWh}$ for small

hydropower

Maximum flow rate of the selected turbine

Minimum flow rate of the selected turbine

Minimum state-of-charge of battery bank

Net head

Nominal voltage of a single PV

Number of batteries in parallel

Number of batteries

Number of days of autonomy, which is

usually between $2-5$ days

Number of devices of appliance $r$ in user

class $q$

Number of devices of appliance $r$ in user

class on standby

Number of small hydropower generating

units

Number of solar photovoltaic panels

Number of solar PV in parallel

Number of solar PV in series

Number of times of battery replacement

Outlet losses

Per capital cost per unit of battery

Per capital cost per unit of charge controller

Per capital cost per unit of small hydropower generating unit

Per capital cost per unit of solar PV

Power consumed by appliance $r$ in user class

$q$
$G_{r e f}$

$r_{1}$

$r_{2}$

$P_{P V}$

$S F F$

$G_{t}$

$\rho$

$P_{q r}^{s b y}$

$E_{t}^{\text {bat }}$
$R$

$T_{\text {ref }}$

$\Delta t$

$T A C$

$E_{t}^{O P}$

$E_{t}^{S H P}$

$E_{t}^{P V}$

$h_{t r}$

LCOE

$C_{I, \text { inv }}$

\section{Acknowledgements}

The authors wish to acknowledge the Director and the entire management team of the National Centre for Hydropower Research and Development (NACHRED), University of Ilorin, Ilorin Nigeria for providing funding and enabling environment in the course of this study. We also appreciate the cooperation of the people of Budo Umoru community for giving needed supports while the hydrological gauge was installed along the river Oshin.

\section{References}

Abdelkader, A., Rabeh, A., Ali, D.M., \& Mohammed, J. (2018). Multi-objective genetic algorithm based sizing optimization of a stand-alone wind/PV power supply system with enhanced battery/supercapacitor hybrid energy. Energy, $163 \quad$ (15) 351-363; https://doi.org/10.1016/j.energy.2018.08.135

Abdul Razak, N. A. b., Murtadha, M., b. O., \& Muslim, I. (2010). Optimal sizing and operation strategy of hybrid renewable energy system using homer. In Power Engineering and Optimization Conference (PEOCO), 23-24 June, Shah Alam, Malaysia; DOI: 10.1109/PEOCO.2010.5559240

Ahmadi, M. H., Ghazvini, M., Sadeghzadeh, M., Nazari, M. A., Kumar, R., Naeimi, A. (2018). Solar power technology for electricity generation: A critical review. Electrochemical sciences advances, wiley online 6(5), 340-361.

Akuru, U. B., Onukwube, I. E., Okoro, O. I., \& Obe, E. S. (2017). Towards $100 \%$ renewable energy in Nigeria. Renewable and Sustainable Energy Reviews 71, 943-953; https://doi.org/10.1016/j.rser.2016.12.123

Amer, M., Namaane, A., \& M'sirdi, N. K. (2013). Optimization of hybrid renewable energy systems (HRES) using PSO for cost reduction. Energy Procedia, 318-327; https://doi.org/10.1016/j.egypro.2013.11.032

Ardakani, F. J., Riahy, G., \& Abedi, M. (2010). Design of an optimum hybrid renewable energy system considering 
reliability indices. In 18th IEEE Iranian Conference on Electrical Engineering (ICEE) May, 842-847; DOI: 10.1109/IRANIANCEE.2010.5506958

Ariyo, B.O., Akorede, M.F., Omeiza, I.O., Amuda, S.A., \& Oladeji, S.A. (2018). Optimization analysis of a stand-alone hybrid energy system for the senate building, university of Ilorin, Nigeria. Journal of Building Engineering 1(19), 285-294; https://doi.org/10.1016/j.jobe.2018.05.015

Askarzadeh, A., \& dos Santos, C. L. (2015). A novel framework for optimization of a grid independent hybrid renewable energy system: A case study of Iran. Solar Energy, 112, 383-396; https://doi.org/10.1016/j.solener.2014.12.013

Aziz, A. S., Tajuddin, M. F. N., Adzman, M. R., Azmi, A., \& Ramli, M. A.M. (2019). Optimization and sensitivity analysis of standalone hybrid energy systems for rural electrification: A case study of Iraq. Renewable Energy 138, 775-792; https://doi.org/10.1016/j.renene.2019.02.004

Azoumah, Y., Yamegueu, D., Ginies, P., Coulibaly, Y., \& Girard P. (2011). Sustainable electricity generation for rural and peri-urban populations of sub-Saharan Africa: The "flexyenergy" concept. Energy Policy 39, 131-141; https://doi.org/10.1016/j.enpol.2010.09.021

Balat, M., \& Balat, H. (2010). Progress in biodiesel processing. Applied Energy 87, 1815-1835; DOI: 10.1016/j.apenergy.2010.01.012

Bashir, M., \& Sadeh, J. (2011). Optimal sizing of hybrid wind/photovoltaic/battery considering the uncertainty of wind and photovoltaic power using Monte Carlo. In 11th IEEE International Conference on Environment and Electrical Engineering (EEEIC) May, 1081-1086; DOI: 10.1109/EEEIC.2012.6221541

Bashir, M., \& Sadeh, J. (2012). Size optimization of new hybrid stand-alone renewable energy system considering a reliability index. In 11th IEEE International Conference on Environment and Electrical Engineering (EEEIC) May, 989-994; DOI: 10.1109/EEEIC.2012.6221521

Boonbumroong, U., Pratinthong, N., Thepa, S., Jivacate, C., \& Pridasawas, W. (2011). Particle swarm optimization for ACcoupling stand-alone hybrid power systems. Solar Energy, 85(3), https://doi.org/10.1016/j.solener.2010.12.027

Borhanazad, H., Saad, M., \& Velappa, G.G. (2014). Optimization of Micro-Grid System using MOPSO. Renewable Energy 71, 295-306; https://doi.org/10.1016/j.renene.2014.05.006

Bourennani, F., Rahnamayan, S., \& Naterer, G. F. (2015). Optimal design methods for hybrid renewable energy systems. International Journal of Green Energy, 12(2), 148159; https://doi.org/10.1080/15435075.2014.888999

Cho, J., \& Kleit, A.N. (2015). Energy storage systems in energy and ancillary markets: a backwards induction approach. Applied Energy, 147, 176-183; http://dx.doi.org/10.1016/j.apenergy.2015.01.114

Coello, C.C., Lamont, G.B., \& Van-Veldhuizen, D.A. (2007). Evolutionary algorithms for solving multi-objective problems. $\quad 2^{\text {nd }}$ ed. New York: Springer; https://www.springer.com/gp/book/9780387332543

Dalton, G.J., Lockington, D.A. \& Baldock, T.E. (2008). Feasibility analysis of stand-alone renewable energy supply options for a large hotel. Renewable Energy, 33(7), 1475-1490; https://doi.org/10.1016/j.renene.2007.09.014

Das, M., Singh, M. A. K., \& Biswas, A. (2019). Techno-economic optimization of an off-grid hybrid renewable energy system using metaheuristic optimization approaches - Case of a radio transmitter station in India. Energy Conversion and Management 185, 339-352; https://doi.org/10.1016/j.enconman.2019.01.107

Das, R., Wang, Y., Putrus, G., Kotter, R., Marzband, M., Herteleer, B., Warmerdam, J. (2020). Multi-objective techno-economic-environmental optimization of electric vehicle for energy services. Applied Energy 257, 113965. https://doi.org/10.1016/j.apenergy.2019.113965.

Demiroren, A., \& Yilmaz, U. (2010). Analysis of change in electric energy cost with using renewable energy sources in Gokceada, Turkey: As island example. Renewable and
Sustainable Energy Reviews, 14(1),

323-33; https://doi.org/10.1016/j.rser.2009.06.030

Eberhart, R., \& Kennedy, J. (1995). A new optimizer using particle swarm theory. MHS'95. In proceedings of the Sixth International Symposium on Micro Machine and Human Science, 39-43. Available on line at: http://dx.doi.org/10.1109/MHS.1995.494215.

Fodhil, F., Hamidat, A., \& Nadjemi, O. (2019). Potential, optimization and sensitivity analysis of photovoltaic-dieselbattery hybrid energy system for rural electrification in Algeria. Energy 169, 613-624; https://doi.org/10.1016/j.energy.2018.12.049

Forough, A. B., \& Roshandel, R. (2017). Multi objective receding horizon optimization for optimal scheduling of hybrid renewable energy system. Energy and Buildings 150, 583597; https://doi.org/10.1016/j.enbuild.2017.06.031

Gao, Y., Du, W., \& Yan, G. (2015). Selectively-informed particle swarm optimization. Scientific reports 5:

Gholinejad, R., Loni, A., Adabi J., Marzband, M. (2020). A hierarchical energy management system for multiple home energy hubs in neighborhood grids Hamid. Journal of Building Engineering 28, 101028. DOI: 10.1016/j.jobe.2019.101028

Hadidian-Moghaddam, M. J., Arabi-Nowdeh, S., \& Bigdeli, M. (2016). Optimal sizing of a stand-alone hybrid photovoltaic/wind system using new grey wolf optimizer considering reliability. Journal of Renewable and Sustainable Energy 8, 035903. Available on line at: https://doi.org/10.1063/1.4950945

Hakimi, S. M., \& Moghaddas-Tafreshi, S. M. (2009). Optimal sizing of a stand-alone hybrid power system via particle swarm optimization for Kahnouj area in south-east of Iran. Renewable energy 34(7), 1855-1862; https://doi.org/10.1016/j.renene.2008.11.022

Himri, Y., Stambouli, A.B., Draoui, B. \& Himri, S. (2008). Technoeconomical study of hybrid power system for a remote village in Algeria, Energy, 33(7), 1128-36; https://doi.org/10.1016/j.energy.2008.01.016

Huang, Z., Xie, Z., Zhang, C., Chan, S. H., Milewski, J., Xiea, Y. Yang, Y., \& Hu, X. (2019). Modeling and multi-objective optimization of a stand-alone PV-hydrogen-retired EV battery hybrid energy system. Energy Conversion and Management, $\quad 181, \quad 80-92$; https://doi.org/10.1016/j.enconman.2018.11.079

Jadidbonab, M., Mohammadi-Ivatloo, B., Marzband, M., Siano, P. (2020). Short-term Self-Scheduling of Virtual Energy Hub Plant within Thermal Energy Market. IEEE Transactions on Industrial Electronics, 1-13. DOI: 10.1109/TIE.2020.2978707.

Kaabeche, A. \& Bakelli, Y. (2019). Renewable hybrid system size optimization considering various electrochemical energy storage technologies. Energy Conversion and Management, 193, 2019, 162-175; https://doi.org/10.1016/j.enconman.2019.04.064

Kamal, B. (2012). Carbon Trading -It Pays to have Green Grid. Paper presented at the International Training Programme on "Rural Electrification with Small Hydropower" for participants from African countries Under India - Africa Forum Summit - II, at Alternate Hydro Energy Centre Indian Institute of Technology, Roorkee, India.

Kamel, S., \& Dahl, C. (2005). The economics of hybrid power systems for sustainable desert agriculture in Egypt. Energy, $\quad 30 \quad$ (8), $1271-81$; https://doi.org/10.1016/j.energy.2004.02.004

Kamjoo, A., Maheri, A., Dizqah, A., \& Putrus, G. (2016). Multiobjective design under uncertainties of hybrid renewable energy system using NSGA-II and chance constrained programming. International Journal of Electrical Power Energy Systems, 74, 187-194; DOI: 10.1016/j.ijepes.2015.07.007

Katsigiannis, Y.A., Georgilakis, P.S., \& Karapidakis, E.S. (2010). Multi objective genetic algorithm solution to the optimum economic and environmental performance problem of small autonomous hybrid power systems with renewable. IET 
Renewable Power Generation 4(5), 404-419; DOI: 10.1049/iet-rpg.2009.0076

Kaveh, K. D., Amir-Reza, A., \& Madjid, T. (2013). A new multiobjective particle swarm optimization method for solving reliability redundancy allocation problems. Reliability Engineering System Safety, 111, 58-75; https://doi.org/10.1016/j.ress.2012.10.009

Kaviani, A. K., Riahy, G. H., \& Kouhsari, S. M. (2009). Optimal design of a reliable hydrogen-based stand-alone wind/PV generating system, considering component outages. Renewable Energy, 34(11), 2380- 2390; https://doi.org/10.1016/j.renene.2009.03.020

Kennedy, J., \& Eberhart, R. (1995). Particle swarm optimizationNeural Networks. Proceedings of IEEE International Conference, 4, pp. 1942-1948. Available on line at: http://dx.doi.org/10.1109/ ICNN.1995.488968.

Khan, M. J., \& Igba, M. T. (2005). Pre-feasibility study of standalone hybrid energy systems for applications in Newfoundland. Renewable Energy 30, 835-854; https://doi.org/10.1016/j.renene.2004.09.001

Kusakana, K., Munda, J. L., \& Jimoh, A. A. (2009). Feasibility study of a hybrid PV-micro hydro system for rural electrification. IEEE AFRICON 2009, 23 - 25 September, Nairobi, Kenya; DOI: 10.1109/AFRCON.2009.5308185

Lan, H., Wen, S., Hong, Y., Yu, D.C. \& Zhang, L. (2015). Optimal sizing of hybrid PV/diesel/battery in ship power system. Applied Energy 158, 26-34; https://doi.org/10.1016/j.apenergy.2015.08.031

Lee, T. Y., \& Chen, C. L. (2009). Wind-photovoltaic capacity coordination for a time-of-use rate industrial user. IET Renewable Power Generation, 3(2),152-167; DOI: 10.1049/iet-rpg:20070068

Limmeechokchai, B., \& Chawana, S. (2007). Sustainable energy development strategies in the rural Thailand: The case of the improved cooking stoves and the small biogas digester. Renewable and Sustainable Energy Reviews, 11(5), 818837; https://doi.org/10.1016/j.rser.2005.06.002

Mahmoudi, S. M., Maleki, A., Ochbelagh, D. R. (2021). Optimization of a hybrid energy system with/without considering back-up system by a new technique based on fuzzy logic controller. Energy Conversion and Management 229, 113723.

Maleki, A., \& Askarzadeh, A. (2014). Optimal sizing of a $\mathrm{PV} /$ wind/diesel system with battery storage for electrification to an off-grid remote region: a case study of Rafsanjan, Iran. Sustainable Energy Technologies and Assessments, 7 ,

$147-53$ https://doi.org/10.1016/j.seta.2014.04.005

Marzband, M., Azarinejadian, F., Savaghebi, M., Pouresmaeil, E., Guerrero, J. M., Lightbody G. (2018). Smart transactive energy framework in grid-connected multiple home microgrids under independent and coalition operations. Renewable Energy 126, 95-106. https://doi.org/10.1016/j.renene.2018.03.021

Masoud, S., \& Tarek, Y. E. (2014). A dynamic MOPSO algorithm for multiobjective optimal design of hybrid renewable energy systems. International Journal of Energy Research, 38(15), 1949-1963; https://doi.org/10.1002/er.3202

Mirzaei, M. A., Sadeghi-Yazdankhah, A., Mohammadi-Ivatloo, B., Marzband, M., Shafie-khah, M., Catalão, J. P. S. (2019). Integration of emerging resources in IGDT-based robust scheduling of combined power and natural gas systems considering flexible ramping products, Energy 189, 116195. https://doi.org/10.1016/j.energy.2019.116195.

Mohamed, M. A, Eltamaly, A. M., \& Alolah, A. I. (2016). PSObased smart grid application for sizing and optimization of hybrid renewable energy systems. PLoS ONE 11(8):e0159702; https://doi.org/10.1371/journal.pone.0159702

Nandi, S., \& Ghosh, H.R. (2010). Prospect of wind-PV-battery hybrid system as an alternative to grid extension in Bangladesh. Energy, 35(7), 3040-3047; https://doi.org/10.1016/j.energy.2010.03.044
Nazari-Heris, M., Mirzaei, M. A., Mohammadi-Ivatloo, B., Marzband, M., Asadi, S. (2020). Economic-environmental effect of power to gas technology in coupled electricity and gas systems with price-responsive shiftable loads. Journal of Cleaner Production 244, 118769, 2020. https://doi.org/10.1016/j.jclepro.2019.118769

Nfah, E. M., Ngundam, J. M., Vandenbergh, M., \& Schmid, J. (2008). Simulation of off-grid generation options for remote villages in Cameroon. Renewable Energy, 33 (5), 1064-72; https://doi.org/10.1016/j.renene.2007.05.045

Perera, A. T. D., Attalage, R. A., Perera, K. K. C. K., \& Dassanayake, V.P.C. (2013). A hybrid tool to combine multi-objective optimization and multi-criterion decision making in designing standalone hybrid energy systems. Applied Energy, 107, 412-425; https://doi.org/10.1016/j.apenergy.2013.02.049

Ren, H., Lu, Y., Wu, Q., Yan, X., \& Zhou, A. (2018). Multiobjective optimization of a hybrid distributed energy system using NSGA-II algorithm. Frontiers Energy, 12(4), 518-528; https://doi.org/10.1007/s11708-018-0594-7

Roberts, J. J., Marotta Cassula, A., Silveira, J. L., da Costa Bortoni, E., \& Mendiburu, A. Z. (2018). Robust multiobjective optimization of a renewable based hybrid power system. Applied Energy, 223, 52-68; https://doi.org/10.1016/j.apenergy.2018.04.032

Sadeghzadeh, M., Ahmadi, M. H., Kahani, M., Sakhaeinia, H., Chaji, H., Chen, L. (2019). Smart modeling by using artificial intelligent techniques on thermal performance of flat-plate solar collector using nanofluid. Energy Science and Engineering, 7(5), 1649-1658.

Sambo, A. S. (2009). The Place of Renewable Energy in the Nigerian Energy Sector. Paper presented at the World Future Council Workshop on Renewable Energy Policies, 10thOctober, Addis Ababa, Ethiopia.

Setiawan, A., Zhao, Y., \& Nayar, C. M. (2009). Design, economic analysis and environmental considerations of mini-grid hybrid power system with reverse osmosis desalination plant for remote areas. Renewable Energy, 34(2), 374-83; https://doi.org/10.1016/j.renene.2008.05.014

Shaahid, S.M., \& Elhadidy, M.A. (2007). Technical and economic assessment of grid-independent hybrid photovoltaic-dieselbattery power systems for commercial loads in desert environments. Renewable and Sustainable Energy Reviews, 11(8), 1794-1810; https://doi.org/10.1016/j.rser.2006.03.001

Sharafi, M., \& ELMekkawy, T. Y. (2014). Multi-objective optimal design of hybrid renewable energy systems using PSOsimulation based approach. Renewable Energy 68, 67-79.

Singh, R., Bansal, R. C. (2019). Optimization of an Autonomous Hybrid Renewable Energy System Using Reformed Electric System Cascade Analysis. IEE Transactions on Industrial Informatics, $15(1), \quad$ pp. 399-409. https://doi.org/10.1109/TII.2018.2867626.

Starke, A. R., Cardemil, J. M., Escobar, R., \& Colle, S. (2018). Multi-objective optimization of hybrid CSP+PV system using genetic algorithm. Energy, 147(C), 490-503; https://doi.org/10.1016/j.renene.2014.01.011

Suhane, P., Rangnekar, S., Mittal, A., \& Khare, A. (2016). Sizing and performance analysis of standalone wind-photovoltaic based hybrid energy system using ant colony optimization. The Institution of Engineering and Technology, 10(7), 964972; DOI: 10.1049/iet-rpg.2015.0394

Tregambi, C., Bareschino, P., Mancusi, E., Pepe, F., Montagnaro, F., Solimene, R., Salatino, P. (2021). Modelling of a concentrated solar power - photovoltaics hybrid plant for carbon dioxide capture and utilization via calcium looping and methanation. Energy Conversion and Management, 230,113792 .

Tsai, T-C., Beza, T. M., Molla, E. M., Kuo, C-C. (2020). Analysis and Sizing of Mini-Grid Hybrid Renewable Energy System for Islands. IEEE, 8, 70013- 70029. https://doi.org/10.1109/ACCESS.2020.2983172

Turkey, B.E. \& Telli, A.Y. (2011). Economics analysis of standalone and grid-connected hybrid energy systems. 
Renewable Energy, $\quad 36(7), \quad$ 1931-1943; https://doi.org/10.1016/j.renene.2010.12.007

Wang, L., \& Singh, C. (2009). Multicriteria design of hybrid power generation systems based on a modified particle swarm optimization algorithm. IEEE Transactions on Energy Conversion, 24(1), 163-172; 10.1109/TEC.2008.2005280

Weis, T. M., \& Ilinca, A. (2008). The utility of energy storage to improve the economics of wind-diesel power plants in Canada. Renewable Energy, 33(7), 1544-1557; https://doi.org/10.1016/j.renene.2007.07.018

Wu, T., Bu, S., Wei, X., Wang, G., Zhou, B. (2021). Multitasking multi-objective operation optimization of integrated energy system considering biogas-solar-wind renewables. Energy Conversion and Management, 229, 2021, 113736. https://doi.org/10.1016/j.enconman.2020.113736.

Zahraee, S. M., Assadi, M. K., \& Saidur, R. (2016). Application of artificial intelligence methods for hybrid energy system optimization. Renewable and Sustainable Energy Reviews, 66, 617-630; https://doi.org/10.1016/j.rser.2016.08.028

Zakeri, B., \& Syri, S. (2015). Electrical energy storage systems: a comparative life cycle cost analysis. Renewable and Sustain Energy Reviews 42, pp. 569-596. Available on line at: http://dx.doi.org/10.1016/j.rser.2014.10.011.

Zhao, P., Wang, J., \& Dai., Y. (2015). Capacity allocation of a hybrid energy storage system for power system peak shaving at high wind power penetration level. Renewable Energy 75, pp. 541-549. Available on line at: http://dx.doi.org/10.1016/j.renene.2014.10.040

Zhu, J. (2015) Optimization of power system operation. Vol. 47. John Wiley \& Sons, 2015. https://www.wiley.com/enus/Optimization+of+Power+System+Operation $\% 2 \mathrm{C}+2 \mathrm{nd}+$ Edition-p-9781118854150

(C) 2021. This article is an open access article distributed under the terms and conditions of the Creative Commons Attribution (CC BY) license (http://creativecommons.org/licenses/by/4.0/) 